九州大学学術情報リポジトリ

Kyushu University Institutional Repository

\title{
Nano-Particles Additives as a Promising Trend in Tribology: A Review on their Fundamentals and Mechanisms on Friction and Wear Reduction
}

Anthony Chukwunonso Opia

Automotive Development Centre, School of Mechanical Engineering, Universiti Teknologi Malaysia

Mohd Kame il Abdul Hamid

Automotive Development Centre, School of Mechanical Engineering, Universiti Teknologi Malaysia

Syahrullail, Samion

Automotive Development Centre, School of Mechanical Engineering, Universiti Teknologi Malaysia

Charles A. N. Johnson

Department of Marine Engineering, Niger Delta University

他

https://doi.org/10.5109/4742121

出版情報 : Evergreen. 8 (4)，pp.777-798，2021-12. 九州大学グリーンテクノロジー研究教育センター バージョン：

権利関係 : 


\title{
Nano-Particles Additives as a Promising Trend in Tribology: A Review on their Fundamentals and Mechanisms on Friction and Wear Reduction.
}

\author{
Anthony Chukwunonso Opia ${ }^{1,2}$, Mohd Kameil Abdul Hamid ${ }^{1}$, Samion, Syahrullail ${ }^{1}$, \\ Charles A. N. Johnson², Abu Bakar Rahim¹, Mohammed B. Abdulrahman ${ }^{3}$
${ }^{1}$ Automotive Development Centre, School of Mechanical Engineering, Universiti Teknologi Malaysia, Johor Bahru, MALAYSIA
${ }^{2}$ Department of Marine Engineering, Niger Delta University, Wilberforce Island, Bayelsa State, NIGERIA.
${ }^{3}$ Department of Mechanical Engineering, Federal Polytechnic, Mubi, Adamawa State, NIGERIA.

*Author to whom correspondence should be addressed:

E-mail: anthonyopia17@yahoo.com

(Received July 3, 2021; Revised November 29, 2021; accepted November 30, 2021).

\begin{abstract}
Nanoparticles (NPs) additives have gained notable influence in technology advancements owing to their excellent physiochemical properties with enhanced performance in application compared to previously used additives. The field of tribology has contributed significantly towards upgrading the overall engine efficiency through use of lubricating materials. The outstanding technique in achieving this is through adoption of additives derived from nanotechnology capable of preventing friction and wears during engine operations. Since only base oil cannot withstand most of the operating conditions, suitable additives are formulated and blended as to enhance the tribological properties. According to some research, nanoparticle additions have a greater impact on lubricant improvement. The ability to design NPs additives with unique qualities raises the value and demand for such class of products. The purpose of this study is to highlight the promising properties of NPs additives, mechanisms and to define the specific knowledge gaps related to the size of NPs towards friction and wear reduction. The function and mechanism performance of NPs additives during operation, such as mending, rolling, film formation, and polishing effect, is determined by their types. The excellent load carrying capability of nanoparticles during lubrication reflects their outstanding performance. The review presents an overview of the history and classifications of NPs and concisely elucidate their tribological effect when applied in lubrication. Excellent function of nano additives is the attribute of its nanoscale (1 to $100 \mathrm{~nm}$ ) nature, thus categorized base on their size, shape, origin and composition. Certain expected characteristics of lubricating oil like friction and wear resistance, surfactant operation, load carrying capacity, extreme pressure operation, etc. were achieved through inclusion of nanoparticles additives.
\end{abstract}

Keywords: Nano particle additives, classifications, lubrications, mechanisms, friction and wear effect.

\section{Introduction}

In tribology, improving the tribological properties of lubricant has been a serious concern as it affects the working operation of the machine both in power output ${ }^{1,2}$ ) and machine elements ${ }^{3-5}$ ). In recent years, the field of tribology has received rapid positive attention since poor lubrication has evidently show loss of energy and waste of resources resulting from severe friction and wear ${ }^{6-9)}$. Solving this unwanted friction and wear during system operation, which stands as the most confronted challenges during system working operation ${ }^{10)}$. Tribologists have come up with three possible approaches in mitigating the problems. These approaches cover all the tribological system both elements and medium involved during mechanism ${ }^{8,11)}$. First was on machine element surface topography, physio-chemical aspects of solid surfaces and surface interactions as to know suitable material to be used. According to ${ }^{12)}$, achieving smoother topography of gears to superfinishing level ,provide great reduction in friction 
to about $30 \%$. Second thought of system working design and configuration which covers sliding and rolling contact together the operating speed, size and angle of attack (area in operation) ${ }^{8)}$. The last, emphasized on the lubricant nature adaptation considering boundary, hydrodynamic, solid-film and hydrostatic conditions; thus, providing optimum performance. In addition, friction condition on elements with new improved surface coating show significant decrease of about $10-50 \%$ on boundary lubricated contacts and about $90 \%$ for dry contacts ${ }^{13,14)}$. In all these, lubricant adaptation and nature yield optimal result and nano-particle technology stands as promising approach over every other mentioned approaches based on its overwhelming potentials towards friction and wear reduction ${ }^{3,15,16)}$. Among all these, fast ability of nanoparticles additives to build geometries or layers, withstand heat, which cannot easily achieve by any other lubricating mode, distinguished it from other counterpart ${ }^{3,17,18}$ ).

Engineers and researchers have focused on enhancing existing facilities and development of new techniques with formulation of novel materials for better machine operation, along with quality lubricant materials being utilized ${ }^{18-21)}$. In the development of lubricant additives, nanoparticles are a relatively new class as described in Fig. 1. Advanced and modified lubricants can improve productivity via energy saving and extend the life cycle of every machinery. As a result, the objective of this study was on the prevalent properties of nano-particle additives, as well as the principles that explain their superiority and dependability in the field of tribology. Understanding the lubricant, friction, and wear relationship during lubrication is important. According to ${ }^{22)}$, tribological system in operation consists of four supportive elements as illustrated in Fig. 2. The two opposite elements surfaces slide against each other, represent the two bodies in operation. Another inclusive element, comprises of the environmental conditions such as humidity and temperature ${ }^{22)}$. The third is the interfacial medium, termed the lubricant (liquid, solid, gas or combined state), however, the developed intermediate layer of film stands as the fourth element and highly important during lubrication ${ }^{19)}$. The response of these aforementioned tribological elements from their interactions and properties yield the resulting friction and wear thus not intrinsic material properties of the system.

Presence of material with good thermal properties and lubricant enhancement features, between the two sliding surfaces in contact, apparently is the possible method of mitigating the unwanted friction, thus prevent wear occurrence ${ }^{5,10,16,23)}$. Furthermore, the use of a proper lubricant in both industrial and domestic applications can serve as debris removers and provide cooling to the machine through surfactant operation ${ }^{24)}$. The inability of the lubricant (base oil and additives) to perform the designed function, lead to manifestation of friction and wear during machine operation 15,22,25). Knowing that friction arises from resistance to motion of a body in sliding or rolling contact with another body whether static or dynamic and proportional to the applied force, but independent of the rolling contact surface area ${ }^{26) 27}$. It is very empirical to understand the cause of friction and wear as to ascertain the suitable lubricant and form to be applied. The following conditions should be well understood and considered. During the sliding mechanism together lubrication, friction takes place over little contact area with temperature at the sliding asperity contact increase to severe rate ${ }^{22,28)}$. With this excessive heat if not controlled by lubricant, could lead to micro-structural changes to asperities with local melting. However, during sliding and lubrication, the main area of contact is influenced mainly by the applied force (load) and speed, thus with inadequate lubrication could cause plastic deformation until the area is great enough to support the load and speed 29). Also at the asperity point with inadequate lubricant, adhesions and welding together among the two surfaces and only the frictional force required to shear the formations ${ }^{9}$. Wear on the other hand refers to as physical loss of machine element materials resulting from poor function of interfacial fluid film of the lubricant ${ }^{10}$. The wear of element materials arises from different factors like; contact fatigue, adhesion, corrosion and abrasion resulting from poor lubricant (base oil and additives) ${ }^{30}$. Solving most of these wear occurrences during sliding operation centered on selecting materials that do not bond together easily, increasing the lubricant film thickness and using improved materials with low shear strength additives layer 9,31). Following all these aforementioned properties required, nano materials provide and stands as last resort in solving the friction and wear challenges during machine sliding operation.

It is very empirical to understand the cause of friction and wear as to ascertain the suitable lubricant and form to be applied. The following conditions should be well understood and considered. During the sliding mechanism together lubrication, friction takes place over little contact area with temperature at the sliding asperity contact increase to severe rate ${ }^{22,28)}$. With this excessive heat if not controlled by lubricant, could lead to micro-structural changes to asperities with local melting. However, during sliding and lubrication, the main area of contact is influenced mainly by the applied force (load) and speed, thus with inadequate lubrication could cause plastic deformation until the area is great enough to support the load and speed ${ }^{29}$ ). Also at the asperity point with inadequate lubricant, adhesions and welding together among the two surfaces and only the frictional force required to shear the formations ${ }^{9}$. Wear on the other hand refers to as physical loss of machine element materials resulting from poor function of interfacial fluid film of the lubricant ${ }^{10}$. The wear of element materials arises from different factors like; contact fatigue, adhesion, corrosion and abrasion resulting from poor lubricant (base oil and additives) ${ }^{30,32)}$, which are normally provided by nanofluid. Solving most of these wear occurrences during sliding 
operation centered on selecting materials that do not bond together easily, increasing the lubricant film thickness and using improved materials with low shear strength additives layer ${ }^{9,31)}$. Problems of poor contact separation are always prevalent in lubricants without nanoparticles, however nanoparticles were discovered to have the

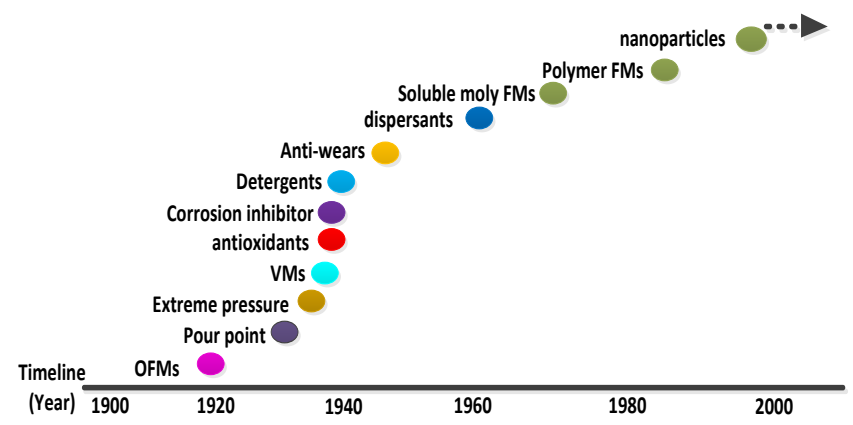

Fig. 1: Chart for development of lubricant additives ${ }^{33) 16)}$

\subsection{Fundamental of Nano-Particle Additives}

\section{in Lubrication}

Nano is a prefix, applied in dimension description of materials within the range of 1 to $100 \mathrm{~nm}$. Nano as in nanotechnology was first mentioned by Nobel laureate Richard P Feynman of physics in his famous work entitled “There's plenty of room at the bottom' in 1959 at American Physical Society meeting ${ }^{34,35)}$. Today nano materials has become great resources in all field of production with huge outstanding potential. Nanotechnology for the formulation of nano materials comprises of manipulation, treatment and creation of materials within the nanometer scale, which could be through scaling from unit to groups of atom or through processing by reducing the bulk size material into the desirable dimension ${ }^{15,36,37)}$. However, nanotechnology in the field of tribology is focused on materials in particulate substances rather than building to group and could be of $1 \mathrm{D}, 2 \mathrm{D}$ or 3D depending on the material type and behavior ${ }^{38)}$. Accordingly, 1D nanomaterials are characterized with single dimension in the nanoscale range, normally found in surface coatings and thin film nanomaterials ${ }^{21}$. These are usually applied in the field of tribology, chemical and biological sensors, fiber optic systems etc. In the case of potential to penetrate contact areas, resulting in body to body separation. Following the requirements for all of the aforementioned features, nanomaterials provide and serve as a final resort in resolving friction and wear challenges. during machine sliding operation

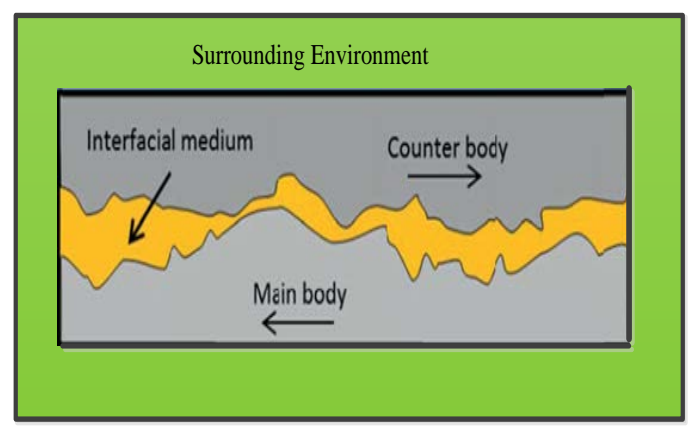

Fig. 2: Diagrammatic representation of the tribological operating system ${ }^{19,22)}$

2D nanomaterials which are found in two dimensions of nanometer scale, normally of nanotubes, nanowires, dendrimers, fibers and fibrils. Also, some free particles of large aspect ratio of nanoscale dimensions are considered 2D nanomaterials during classifications. The manufacturing of 2D nanomaterials are less advanced and their behaviors together chemical properties are more complicated with less understanding. In the application, thin films due formed in various mechanisms which can be grow at a monolayer ${ }^{10,21,37)}$. For $3 D$ nanomaterials, its nanoscale was observed to be in three dimensions. The materials of this form include nanocrystals or quantum dots, colloids, fullerenes, particles and precipitates ${ }^{21,39)}$. This class of nanomaterials are mostly found in tribology and combustion products like natural nanomaterials, titanium oxides ( $\mathrm{TiO}$ ), carbon black, and zinc oxide ( $\mathrm{ZnO}$ ). In the production of some of the products of this class like quantum dots and fullerenes gives high challenges with properties behavior are difficulty to ascertained 5,9,40). Different structure of various nano-additives under microscopic view are shown in Figure 3. 

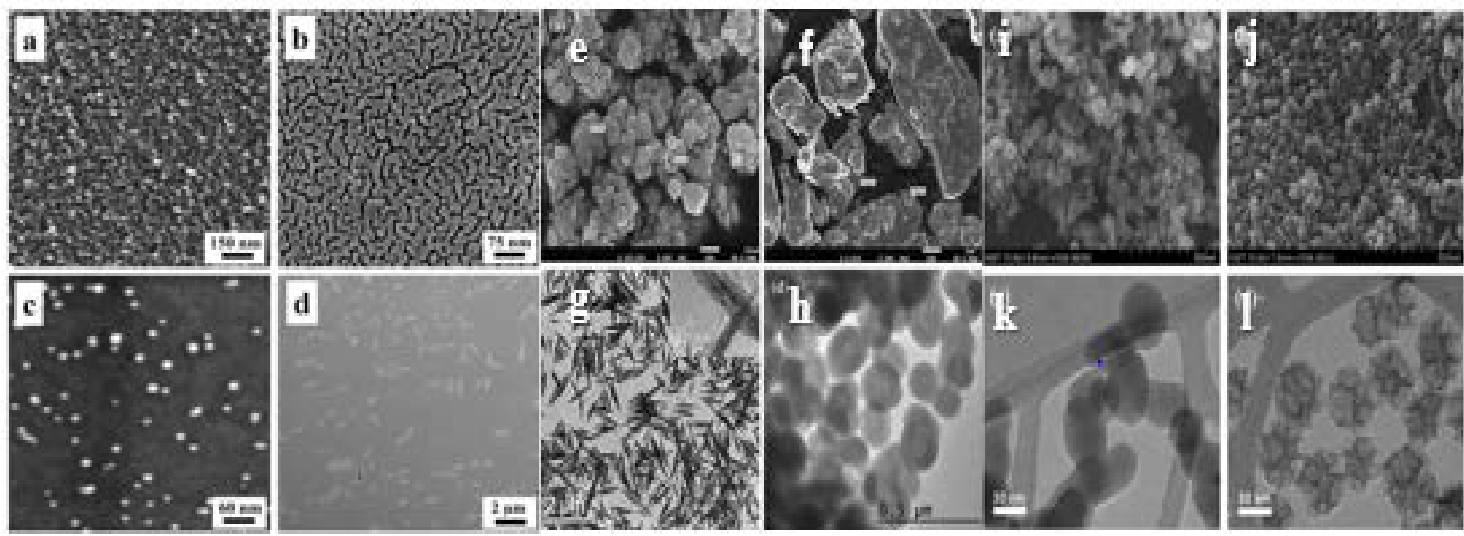

Fig. 3: Image of Scanning microscope (SEM) indicating (a) film of Ti NPs, (b) a near percolating Au film, (c) monodispersed Cu NPs and (d) Fe nano-rods ${ }^{41}$. Morphology of nanoparticles FESEM for, (e) nano $\mathrm{CuO}^{42}$ ), (f) nano $\mathrm{MoS}_{2}{ }^{42}$, HRTEM for (g) nano

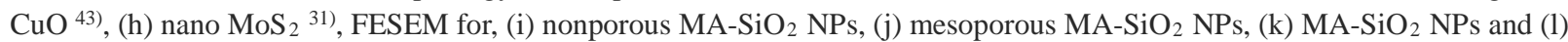
mesoporous $\mathrm{MA}-\mathrm{SiO}_{2}$ NPs $\left.{ }^{39}\right)$

The structure and constituents of nanomaterials are simple atoms or molecules itself but consist of different layers of three forms ${ }^{21)}$; as shown in Fig. 4, which include; 1. The layer surface which are commonly described as Janus NPs in most literature, comprises of two types of nano-particles having common interface but of different form ${ }^{36)}$. The formation of this form of nano-particles tends to reduce the number of the formed bond among the elements (A and B) in the system, illustrated in Fig. 4 (i). The layer surface has potential of functionalization with other close related small molecules of organic material, inorganic material, surfactant, polymers and metal ions. 2. Mixed shell structure which are different in chemical properties from the core in every application. This can be in ordered or random form. Orderly mixed or randomly mixed with alloys arranged in A and B atoms or solutions of solids as case may be, see Fig. 4 (ii). 3. The core-shell structure, which comprises of one type of atom say ' $A$ ' enveloped a core of different atom say ' $B$ ' as in Figure 3 (iii). This form of formation is donated by A@B and found mostly in NPs formulations of multiple shell like onion structure ${ }^{44)}{ }^{45}$ ). The functionalization mostly of alternating like A-B-A shell or A-B-C arrangement when there is ternary NPs, illustrated in Fig. 4 (iv). The development of new structure of latter are normally from structure of three different elements like Fe-Ag-Si multi-shell arrangement thus formulated by adjusting the analysis selected conditions $\left.{ }^{46)} 45,47\right)$. The characteristics are different from others but highly supportive during thermal activities ${ }^{47}$.

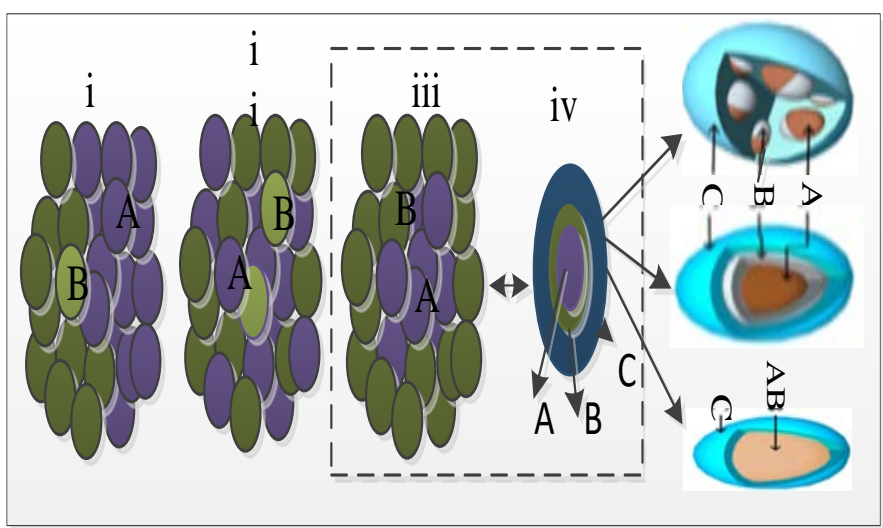

Fig. 4: Schematic description of NPs of different formation structures, (layer surface structure (i), Mixed shell structure(ii), and coreshell (iii or iv) ${ }^{21,44,46)}$

NP additives base on their source, physiochemical and formulation function are differently like anti-wear (AW), friction modifier (FM), extreme pressure (EP), surfactant and viscosity improver polymer, thus enables the base oil lubricant to withstand the working conditions ${ }^{16,48)}$. Apart from numerous physiochemical properties of NP additives, tiny size nature is another important reason of recommending NP in tribological application because of its easy movement on the contact areas leading to good lubricating result ${ }^{10,49,50)}$. In addition, the size enables the lubricant passes through small orifices of engine components like nozzles, injectors and filter elements ${ }^{33,50)}$.

Generally, according to literatures, the microscopic 
nature of the nano-materials observed to be the cardinal reason of their novel physiochemical properties that promote the wide economic benefits and applications ${ }^{10,45)}$. The actualization of the prime feature of these nanomaterial additives were through utilization of some modern nano-technological equipment, following top down approach as seen in Fig.5, while Fig. 6 shows the image of ball mill machine P100 as the commonest technique of formulating NPs. For good formulation of nanoparticle, appropriate step most be followed as to achieve optimal functional group of the sample ${ }^{15,37)}$.

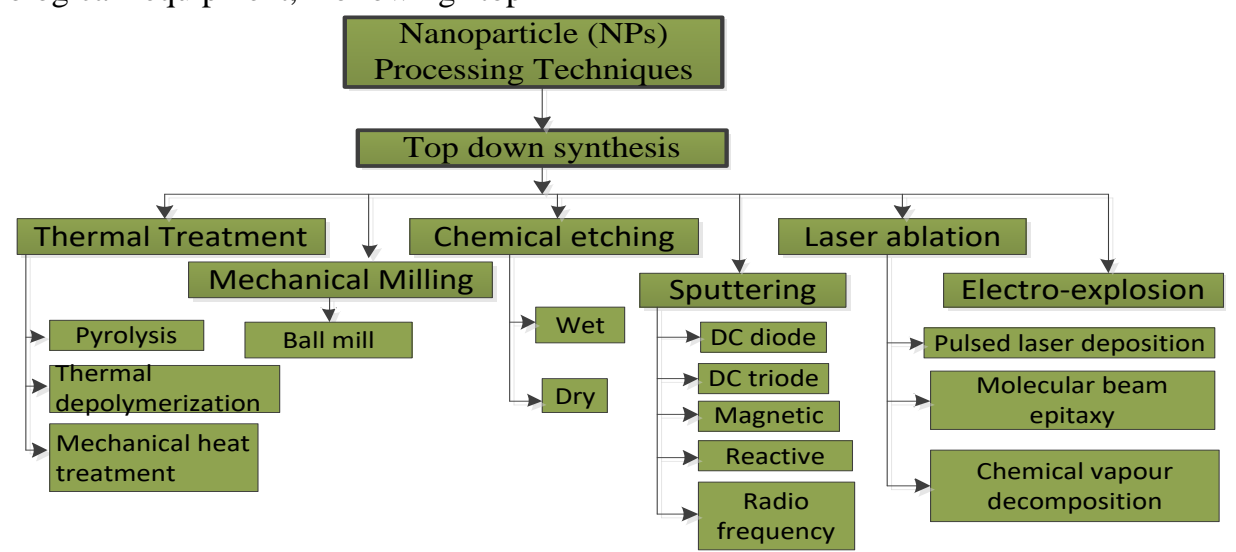

Fig. 5: Production techniques for NPs using top down synthesis approach ${ }^{21)}$.
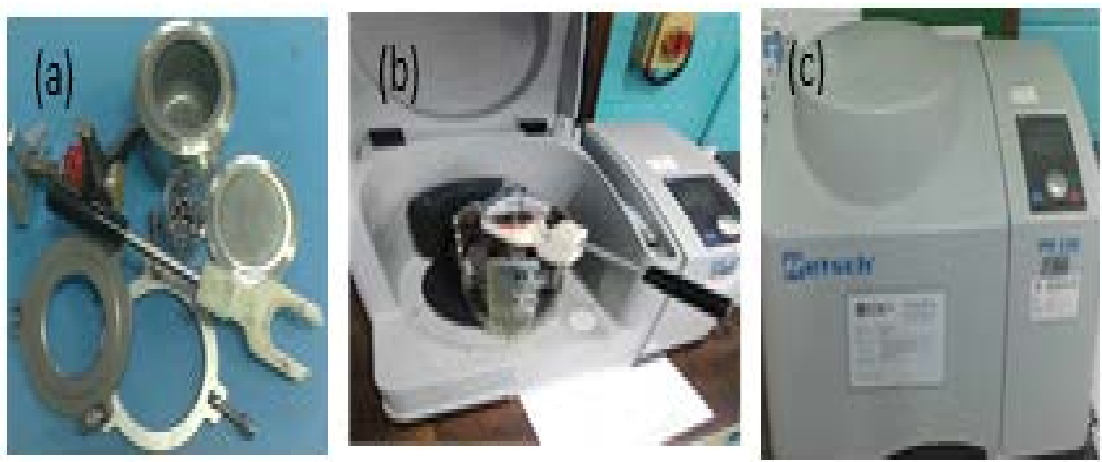

Fig. 6: Image of grinding/ball milling technique for NPs formulation, (a) machine accessories, (b) jar locking step, (c) machine in operation.

This top down approach follows destructive principle, starting from larger molecule, breaks down to smaller unit, at times, uses the generated units to formulate suitable NPs. NP additive performance in base oil depends on some serious factors ranging from morphology, compatibility with the base oil, and size ${ }^{51)}$ thus stands as challenge during application. Thermal treatment is a remedial approach where materials are being heated to increase the mobility and facilitate the extraction of its required contents. It can be classified into many groups; pyrolysis, thermal decomposition and mechanical heat treatment. In pyrolysis, the initiating materials are burn using heat, and may be in liquid or vapor but mostly liquid. It is being processed inside furnace $t$ high pressure, thereby collect the formulated nanoparticles. In some operation, plasma or laser are used in place of flame to generate required temperature. In thermal decomposition, the chemical bond in the compound is broken through an endothermic process. The temperature decomposition is defined so that the element will be chemically decomposed ${ }^{52)}$. The method of mechanical milling is a technique best described using grinding/ball milling machine, fast de-binding and other decomposition methods ${ }^{53)}$. The milling approach was employed as to form powders from the raw materials with the help of ceramic balls and well-known planetary mill. The overall morphology and size of the NPs are normally obtained through different characterization techniques like FESEM, TEM, SEM and particle size analyzer.

The technique of chemical etching/industrial etching or chemical milling is a manufacturing process of using baths of temperature regulated to extract materials or create a new material with unique desired shapes. The wear resistance of the honed $\mathrm{Al}-\mathrm{Si}$ alloy cylinder were improved through chemical etching by applied on the surface of the Al-Si ally samples ${ }^{54)}$. Sputtering method is a phenomenon of deposition of NPs through the means of ejection particles from it ${ }^{55)}$. This process comprises of wet and dry, however, annealing is important for the deposition of NPs thin layer. Formulated particles are determined via some factors like; thickness of the layer, temperature, duration of annealing, and substrate ${ }^{55,56)}$. 
Another technique is laser ablation which is a simple method for synthesis of different NPs from different solvent, done by submerge different materials (metal) in solution by laser beam condense a plasma for the formulation of NPs ${ }^{57,58)}$. This technique still comprises of three other methods like; pulsed laser deposition, molecular beam epitaxy and chemical vapor decomposition ${ }^{5)}$. More importantly, during change in nano-material nature through inter-reaction with other materials, turn from bulk to molecule or macro to nano during shrinking, thus adversely affect their fundamental properties. For instance, developed nano material might display unique optical ${ }^{15,59-61)}$ amphipathic, surfactants, and thermal behavior completely different from their bulk, macro or nano material as case may be. In all these

\subsection{Nanoparticles Type and Classifications}

Generally, NPs type and classification are organized into many different categories (composites, inorganic, organic, ceramics and carbon based nanomaterials) according to their size, nature and application ${ }^{21,41,65)}$. Following these features, NPs source include natural, incidental and engineered nanomaterials. Since this work focused on lubrication, the work will be limited only on engineered aspect of NPs

\subsection{Composites Nanoparticles.}

Composite as NPs are advance materials discovered to be the most outstanding nanoparticle for future application. The product is formulated from two or more different constituent unit material with different in physiochemical properties and when combined form one product with characteristics different from the initiated individual components. ${ }^{15)}$. It consists of curing phase or a matrix and particles in nanoscale with purpose of tribological enhancement ${ }^{60) 37}$ ). The benefit of having the composite NPs materials planned in advance gives them or recommendation and the properties mainly depends on the matrix choice, curing, shape and orientation. Many presentations have it that friction and wear properties of polymeric materials can be enhanced through high stiffness, lower adhesion and strength ${ }^{33,66)}$. In performing the operation, suitable fillers were blended, good proportion of graphite also carefully added as to reduce the adhesion. This formulation due allows formation of friction reducing agent of film on the sliding surfaces, thus reduces the coefficient of friction (COF) in the operation 67). The use of polymer with high temperature resistance supplement (carbon nanotubes matrix) are recommended since friction generates great heat. The combination of these matrix yields composite materials with microstructure of excellent thermal and polymeric behavior. The composite blending with their expected functions are illustrated in the Fig. 7. characteristics formations, size and materials type contribute significantly for the phenomenon ${ }^{62)}$. Although many positive presentations on tribological improvement in lubricants with different nanoparticles, however, the issue of adequate selection of nanoparticles still occur ${ }^{15,38)}$ More so, several works have indicated of possibility of single nanoparticle additive saving more than one purpose as in AW, FM, and EP ${ }^{63,64)}$. According to ${ }^{17,33)}$, pointed some fundamental criterial of NP that makes them advantageous in tribology like; (a) Low reactivity with other included additives; (b), More durability, (c), Insolubility in non-polar base oil, (d). High non volatility to withstand thermal condition, (e). Easy formation of film on different material surface.

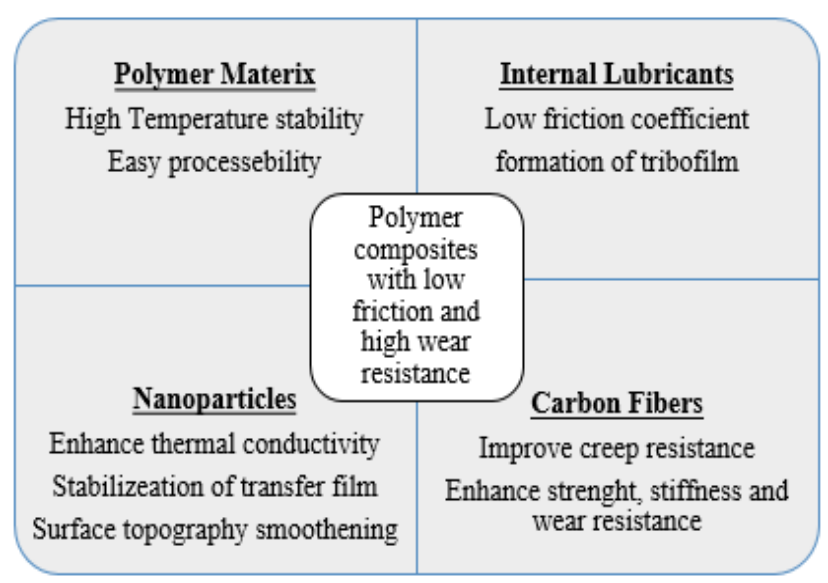

Fig. 7: Formulation of Polymer composites for optimal lubrication

\subsection{Inorganic nanoparticles}

This group of nanoparticles are classified into metal and metal oxide nanoparticles. Inorganic nanoparticles are mostly hydrophilic and biocompatible during lubrication and highly stable than organic nanoparticles. However, they are not mostly toxic particles due carbon products are not present in the list of inorganic nanoparticles.

\subsubsection{Metal nanoparticles}

Currently, metal nanoparticles are considered to the widely used additive in the field of engineering in many applications like in magnetics, semiconductors, photonic and catalysts operation ${ }^{5,68}$. They are used during metallic nanoparticles synthesis through constructive or destructive approach ${ }^{52)}$. In tribology, some interesting engineering properties found in metal nanoparticles pulls the attention of researcher towards utilization of such materials. Metal precursors are best use for formulation of pure metal nanoparticles and always exhibit unique properties because of their resonance characteristics. The persistence use of $\mathrm{Cu}$ nanoparticles provides excellent function especially in the area of self-repairing services together its eco-friendly attribute ${ }^{69-72)}$. On the other hand, 
because of some poor physiochemical properties of these metal nanoparticles products, like weak compatibility in non-polar base oil as a result of high surface activity thus due control through further surface modification approaches ${ }^{52}$ ). In a work presentation by ${ }^{73)}$ on the effect of metal nanoparticles of different types using mineral base oil was conducted. During the study, ${ }^{74)}$ the different metals like $\mathrm{Cu}, \mathrm{Co}$ and $\mathrm{Fe}$ were tested on their respective mixtures, with investigations to determine wear strength of the aforementioned metal materials as seen in Fig. 8.

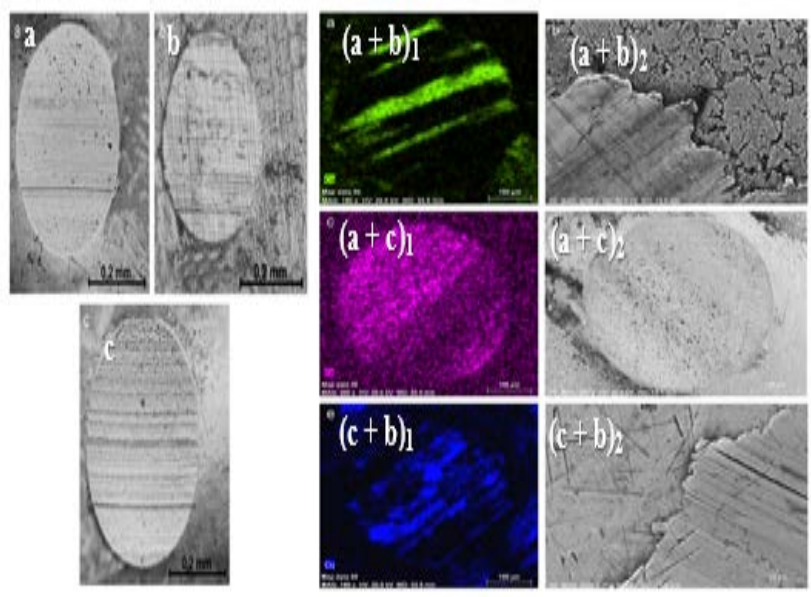

Fig.8.: Image of wear scars on balls operated with SAE 10 oil with different metallic additives: (a) Fe nanoparticles, (b) $\mathrm{Cu}$ nanoparticles, (c) Co nanoparticles, also with mixtures of nanoparticles: $\mathrm{Fe}+\mathrm{Cu}(\mathrm{a}$ and b), $\mathrm{Fe}+\mathrm{Co}(\mathrm{a}$ and $\mathrm{c}$ ) and $\mathrm{Co}+\mathrm{Cu}(\mathrm{c}$ and b). ${ }^{73)}$.

Nanoparticles of $\mathrm{Cu}$ on its tribological behavior on diesel oil using serpentine powder was conducted ${ }^{74)}$. The result shows $7.5 \%$ concentration of $\mathrm{Cu}$ nanoparticles gives wear reduction with maximum friction generation discovered. The ability of metal particles to exhibit all these distinctive features is because of their nanoscale (10$100 \mathrm{~nm})$, surface charge density, pore size, structure (amorphous and crystalline), surface area to volume, environmental factor (heat, moisture) and various shapes (tetragonal, irregular, hexagonal, spherical, cylindrical and rod). However, when the various metal constituents were mixed, surface investigation on the wear scar show improvement on the friction and wear reduction and was so because of their unique properties and resonance characteristics contributed by various metals ${ }^{74)}$. After the mixture of $\mathrm{Fe}$ or $\mathrm{Co}$ with the $\mathrm{Cu}$ nanoparticles, the $\mathrm{Cu}$ nanoparticles occupied the surface and used in the medium as friction resistance ${ }^{73) 74}$. The nano nature of the additives contributes to high performance by altering the friction situation from sliding to rolling by diffusing into the sliding contact ${ }^{75)}$. Nanoparticles bear a portion of the load and form a layer between the two surfaces to avoid adhesion when the lubricant film between tribo-pairs thins and mixes, increasing anti-wear and friction reduction tribological characteristics ${ }^{75)}$.

\subsubsection{Metal oxide nanoparticles}

This class of nanoparticles are from metal oxides and normally synthesized as to modify the property of the individual metals nanoparticles. Example is iron oxide nanoparticles developed from iron nanoparticle through oxidation. As in their function ability, the iron oxide nanoparticles reactivity is high when compared to ordinary iron nanoparticles. As to obtain high reactive and efficiency in operation, metals are synthesized like, cerium oxide, zinc oxide, magnetite, iron oxide silicon oxide and titanium oxide ${ }^{76-78)}$.

\subsection{Ceramic nanoparticles}

The class of this nanoparticles are also referred to as non-metallic solid. They are also amorphous, hollow form and porous when synthesized through successive cooling or heating ${ }^{79}$. Ceramic nanoparticles have attracted great attention, since they always successfully lubricated by water. Also discovered tribo-chemical reaction on the ceramic surface, thus found demonstrated that electric double layer of water film significantly provide super lubricity condition ${ }^{80)}$.

\subsection{Organic nanoparticles}

Organic nanoparticles/nanomaterials are mostly product from organic matter. The materials are not toxic, biodegradable and due possess feature of like hollow sphere like in liposome/lipid and micelles, as seen in Fig. 9. Other product of organic nanomaterials includes dendrimers, and ferritin. The arrangement is by noncovalent interactions for the design of the molecules due transform the particles into the desired structures. Also, polymers are always referred to as organic nanoparticles ${ }^{81)}$. They are of matrix particles with overall mass almost of solid with other adsorbed molecules at the outer boundary of the spherical surface. From their functionalization, applied in lubricant as viscosity improver base on its ability of increase in strength with temperature ${ }^{82) 66)}$. In the case of lipid, always of diameter from 10 to $1000 \mathrm{~nm}$ similar to polymer, possess core solid form of matrix contain soluble lipophilic molecules. In lubricant operation, they function as emulsion or surfactant ${ }^{81)}$. 

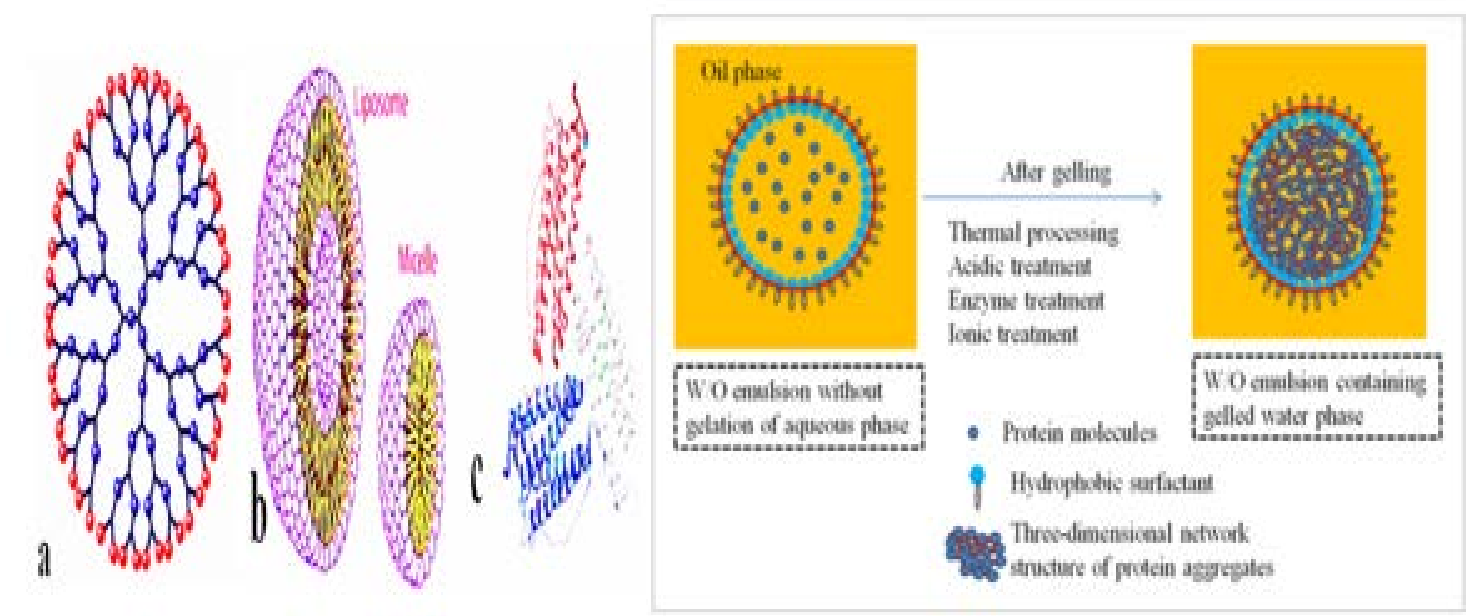

Fig. 9: Image of organic nanoparticles: (a)Dendrimers, (b) Liposomes and Micelles (c) Ferritin ${ }^{21)}$ and (d) W/O emulsions stabilized with gelled water phase ${ }^{81,83)}$.

Current investigation described appealing gelling (organic) approach for formulating W/O emulsions. In the study, applied glucono- $\delta$-lactone (GDL) to initiate the gelation of casein dispersion ( $3 \%$, w/v) instead of thermal method as shown in Fig. 10. When compared the result with W/O emulsion without inner gelation of casein
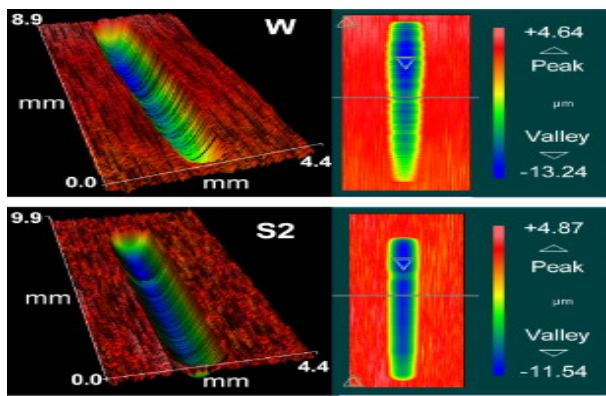

dispersion, evidently show that GDL induced exhibited great resistance to destabilization ${ }^{83)}$. According to ${ }^{84)}$ reported that Surfactant inclusion in base oil has an excellent performance, reducing the friction coefficient of water up to $80 \%$ under the experimental conditions utilized
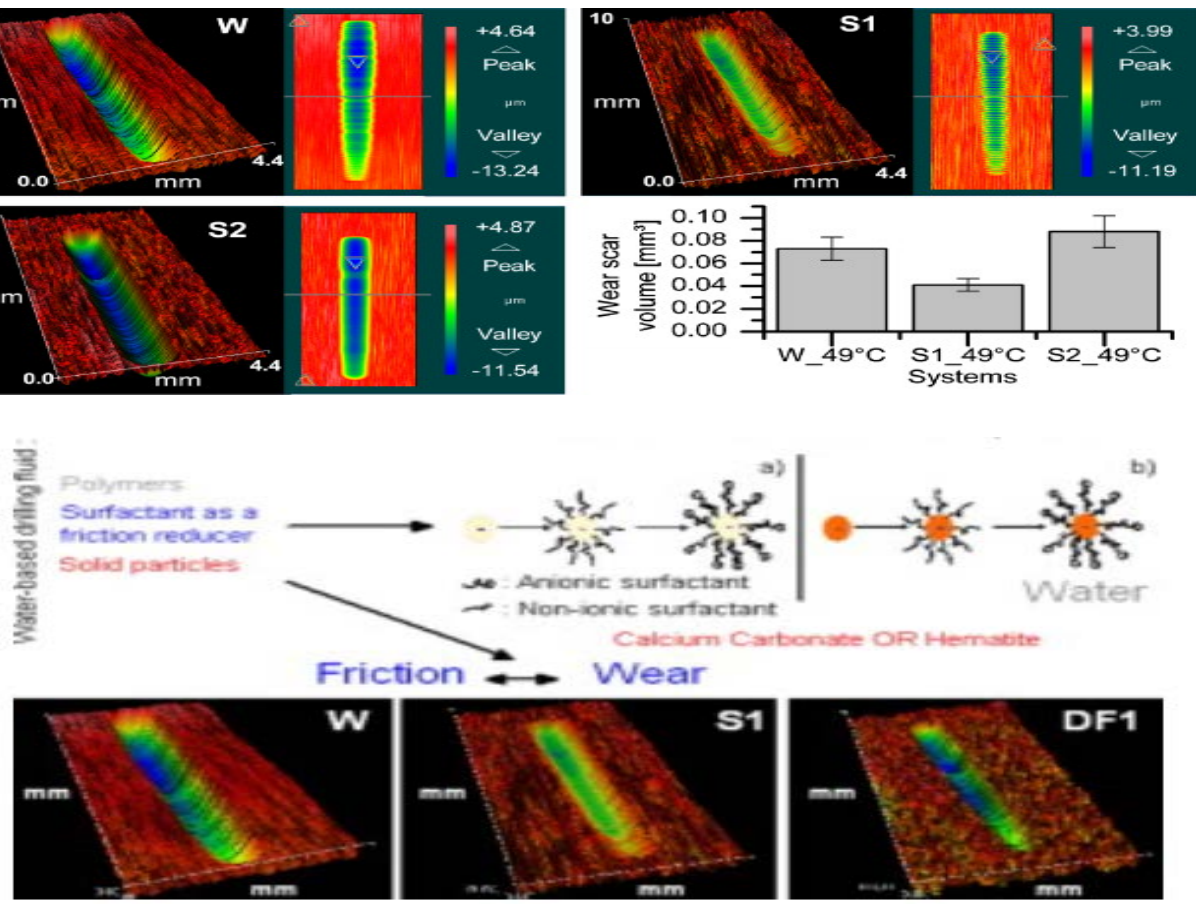

Fig. 10: Optical surface profile images of the metal block after the wear test for the surfactant operation ${ }^{84)}$.

Drilling fluid formulations without inclusion of surfactant additive produce similar result of coefficient of friction compared to water. With inclusion of additive (S1) (surfactant), at $1 \%(\mathrm{w} / \mathrm{v})$, the formulation produced significant reduction in coefficient of friction (COF) by about $60 \%$ compared water. Also, with $0.4 \%$ (w/v) surfactant (S2), reduction turn to $30 \%$ with wear scar formation due to little of surfactant to adsorb by the metal material ${ }^{84)}$, thus concluded that surfactant mixture in aqueous solution provide excellent anti-ear properties for reduction of friction and wear.

\subsection{Carbon base nanomaterials/nanoparticles}

Products of this class, completely composed of carbon 
like, graphene, fullerenes, carbon nanofibers and carbon black $^{15,85)}$, normally found in morphologies such as spheres/ellipsoids and hollow. The popular method for the production of carbon base nanomaterials were chemical vapor deposition (CVD) and laser ablation, with exception of carbon black type ${ }^{86)}$. Series of tremendous works has been presented by researcher's form carbon base nanoparticles towards lubricant properties enhancement with excellent results, owing to their potentials.

\subsubsection{Carbon nanotubes (CNTs)}

These are tubular cylindrical molecules, consist of rolled up sheet of single layer carbon atoms, with structure of about 1-2 nm diameter. Carbon nanotubes can be seen as semiconducting in behavior base on diameter. However, graphene is from carbon in allotropic form of hexagonal network of honeycomb carbon atom of $1 \mathrm{~nm}$ in thickness as see in Fig. 11. The structure of carbon nanotubes base on their rolling can be categorize as single walled (SWNTs), double Walled (DWNTs) and multi-walled (MWNTs). Also carbon nanotubes can form in three ways like; armchair, zig-zag and chiral.

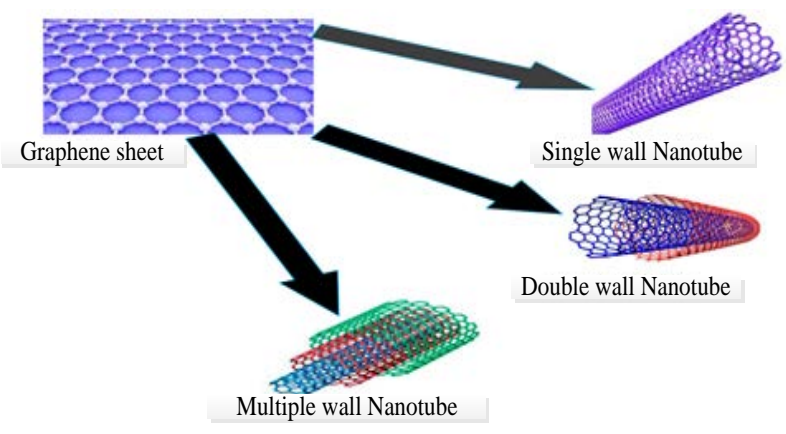

Fig. 11 : Image of graphene sheet rolled into: SWNT, DWNT and MWNT ${ }^{21)}$

As the name implies, SWNTs consist of single rolled sheet of at least $0.7 \mathrm{~nm}$ in diameter, DWNTs consist of double rolled sheet, while that of MWNTs is made up of multiple rolled sheet of at least $100 \mathrm{~nm}$ in diameter. Another class of carbon base material is fullerenes, consist of nanomaterial that looks like hollow cage. This type is more conductive, versatile, electron affinity and even of high strength ${ }^{40,87)}$. Due to their characteristics features, CNTs easily bent and regain its normal figure without brittle. this property made them noteworthy commercially in additive formulation for lubricant application ${ }^{88-91)}$. In the lubricating operation on carbon nanotubes conducted by ${ }^{89,92)}$ on its performance towards friction and wear. Result shows that coefficient of friction with and without CNTs under sliding condition as see in Fig. 12. The result evidently shows that without CNTs coefficient of friction value was 1 , while that of CNTs only dropped to 0.1-0.2 at the same stable period, thus CNTs possesses the potentials to reduce friction and wear.

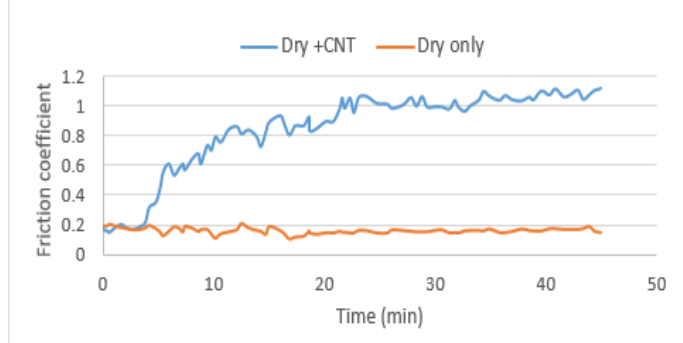

Fig. 12: Coefficient of friction under dry sliding condition with and without CNTs ${ }^{89)}$

The result of this study is also in agreement with the study on Tribological Properties of Novel Multi-Walled Carbon Nanotubes and Phosphorus Containing Ionic Liquid Hybrids in Grease ${ }^{91)}$. Also ${ }^{48)}$, reported that additon of carbon onion additive powder to PAO base oil significantly reduced the friction below 0.1 against 0.15 under pure PAO, likewise graphite exhibiting great reduction on friction as see in Fig. 13. This is because grapite powder is well known for low friction under boundary lubrication as in Fig. 13.
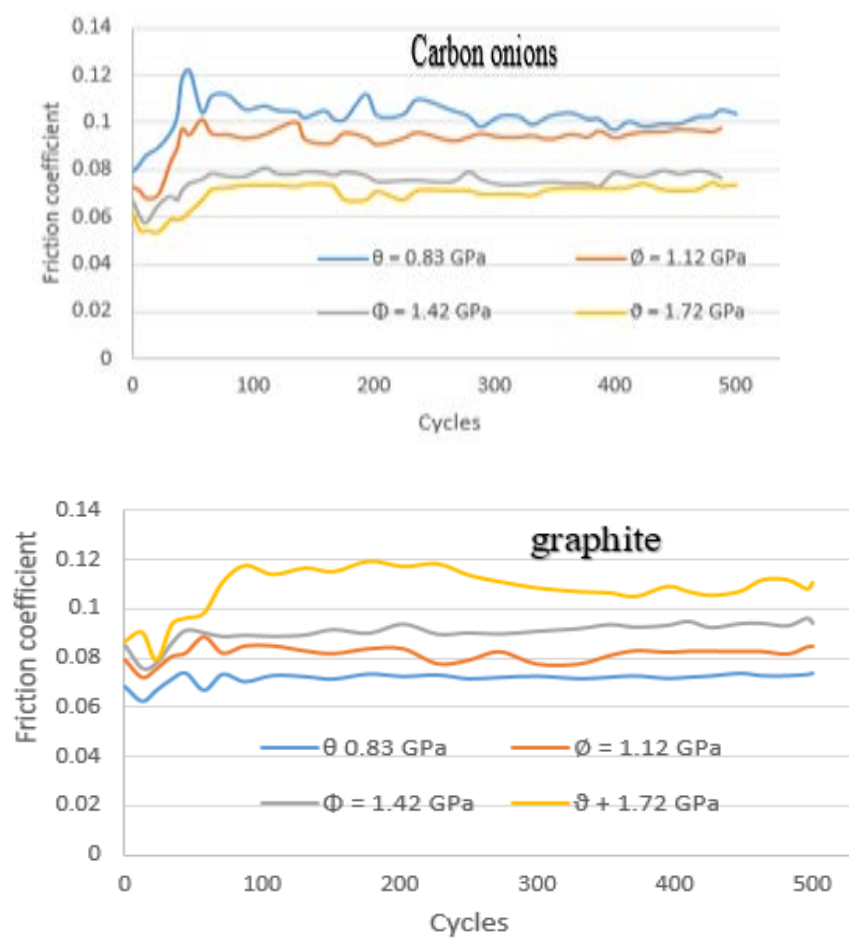

Fig. 13: Friction coefficient obtained at several contact pressure $\quad(0.83-1.72 \mathrm{GPa})$ with the dispersion of $0.1 \mathrm{wt} \%$ in $\mathrm{PAO}$ of carbon onion or graphite ${ }^{48}$ )

\subsection{Carbon nanofiber}

Carbon nanofibers (CNFs) are one of the promising materials in the field of engineering and beyond. Synthesis of carbon nanofibers are usually through chemical vapour decomposition, templating, and electrospinning. In the production, orientation of the carbon layer in CNFs seriously affect its mechanical properties 21,93). Again, 
nano-foils with features of graphene are turn into CNFs as nanotubes, however, the nano-foils are like cone, (see Fig. 14) or cup unlike elongate cylindrical tubes of CNFs ${ }^{15,21)}$.

\subsection{Carbon black}

These are nano-powder produced through high temperature carbonization via a carefully controlled combustion process of about $1300{ }^{\circ} \mathrm{C}$. Its application is verse but mostly in engineering example in ink, green technology and lubrication both coating and in base oil. The shape is mostly spherical with diameter from 20-70 $\mathrm{nm}$ as see in Fig. 14.to differentiate each other.

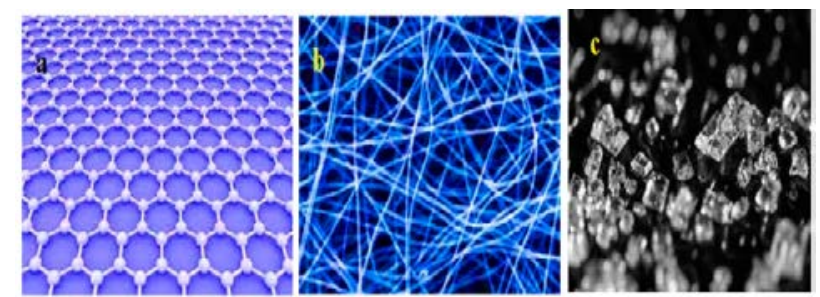

Fig. 14: Image showing (a), Graphene sheet, (b), Carbon nanofiber, (c), Carbon black ${ }^{21)}$.
According to ${ }^{94)}$, carbon black provide smooth sliding with coefficient of friction range from $0.35-0.5$, a volume fraction of at least $13 \%$ of soft nanoparticles. Adding that the particle clusters do not alter the smooth operation, provided the materials are completely embedded in the magnetic matrix. Some of the tribological enhancement performance from the use of some nanoparticles including categories of carbon nanotubes are listed in Table 1 and 2.

Table 1: Summary of Some Important Nanoparticle additive in lubrication

\begin{tabular}{|c|l|c|}
\hline Nanoparticle & Effect & Ref. \\
\hline MWCNT & $\begin{array}{l}\text { MWCNT dispersed with surfactant reduces wear, low } \\
\text { frictional force }\end{array}$ & 95 ) \\
\hline Diamond nanoparticle & $\begin{array}{l}\text { Anti-wear, anti-friction, excellent load carrying capacity as } \\
\text { a result of surface polishing from hard effect of diamond } \\
\text { nanoparticles }\end{array}$ & $96)$ \\
\hline Titanium borate & $\begin{array}{l}\text { Better (NPs) anti-wear property and friction-reducing } \\
\text { property in base oil compared to TiO }{ }_{2} \text { nanoparticles under } \\
\text { the tradition process. }\end{array}$ & $97)$ \\
\hline Diamond Nanoparticle & $\begin{array}{l}\text { Improvement of anti-scuffing performance significantly } \\
\text { reduction in friction }\end{array}$ & $98)$ \\
\hline Diamond nanoparticle & Increasing the friction and wear & $99)$ \\
\hline Nano-cerium borate & Friction modifier & $100)$ \\
\hline Hexagonal boron nitride & Reducing coefficient of friction and scar diameter & $101)$ \\
\hline Diamond nanoparticle & Viscosity increasing effect, friction coefficient decrease & 102) \\
\hline
\end{tabular}

Table. 2: Some research reports on metal matrix/nano carbon (including carbon nanotube and graphene) composites, preparation technique and properties.

\begin{tabular}{|l|l|l|l|l|}
\hline Matrix & Reinforcement & Process & Properties \\
\hline Aluminium & Graphene & $\begin{array}{l}\text { Mixing AA2124 powder and } \\
\text { graphene platelets and then cold } \\
\text { compaction at 525 MPa pressure }\end{array}$ & $\begin{array}{l}\text { Increasing the hardness and decreasing the } \\
\text { relative density. On the other hand, there is } \\
\text { an optimum point that wear rate is } \\
\text { minimized. }\end{array}$ \\
\hline Copper & Nano-graphite & $\begin{array}{l}\text { Powder metallurgy technique } \\
\text { where nano graphite were } \\
\text { dispersed in ethanol and then } \\
\text { copper introduced to solution, } \\
\text { after that drying the powder and } \\
\text { using 450 MPa pressure to make } \\
\text { composite }\end{array}$ & $\begin{array}{l}\text { Copper/nano-graphite exhibit } \\
\text { traction of reinforcement tends to improve } \\
\text { tribological properties }\end{array}$ \\
\hline Aluminium & MWCNT & $\begin{array}{l}\text { High energy ball milling, cold } \\
\text { compaction and hot extrusion }\end{array}$ & $\begin{array}{l}\text { Wear resistance and hardness of composite } \\
\text { significantly increased while CoF decreased }\end{array}$ & 105) \\
\hline
\end{tabular}




\begin{tabular}{|l|l|l|l|l|}
\hline & & $\begin{array}{l}\text { were employed to synthesizing } \\
\text { composite. }\end{array}$ & with significant decrease in wear rate \\
\hline Aluminium & CNT & $\begin{array}{l}\text { Sintering the mixture of } \\
\text { aluminium and CNTs powders in a } \\
\text { carbon mold under 50 MPa } \\
\text { pressure }\end{array}$ & $\begin{array}{l}\text { No change in elongation while there is a } \\
\text { significant improvement in tensile strength. }\end{array}$ \\
\hline
\end{tabular}

\subsection{Mechanism of nanoparticles during} lubrication

Since only base oil lubricant will not withstand operating condition of engine, inclusion of nano particles (additive) into an oil lubricant significantly reduces the system coefficient of friction ${ }^{29,107)}$. The reduction in the friction through the nano particles will apparently increases the load carrying capacity of the contacting components of the mechanical system ${ }^{107,108)}$. When nanoparticles are added into base lubricant oils, new solution that is stable with homogeneous feature is formed 109). In analyzing the nano-particles features and behavior during operation, four different mechanisms have been proposed, described the function and operation towards improvement of the lubricating oil generally ${ }^{30}$ ). They include; rolling mechanism or bearing effect 110,111), protective or tribo film effect ${ }^{112,113)}$, mending effect ${ }^{69)}$ and polishing effect ${ }^{96)}$ as illustrated in Fig. 15.

\subsubsection{Rolling Mechanism or bearing effect}

In the past few years, testing of nano-particles in lubrication have emerged as the best and new choice in additive production. Many reputable works have been conducted using nan-particles, with numerous achievements from the patronize of such products towards enhancement of lubricant tribological properties ${ }^{3,73,114)}$. The mechanism of friction reduction and anti-wear of this form additives clearly believe to perform between the rubbing material surfaces ${ }^{10,69)}$. Experimental work to demonstrate the ball bearing nanoparticle mechanism was conducted by ${ }^{115)}$ using diamond nanoparticles with liquid paraffin. Reported that when experimentation time increased, diamond nanoparticles spherical shape turns into small rolling material like ball bearing and operate in such mechanism as see in Fig.15 and 16. Also, material with rough surface sliding due observe nanoparticles deposit in troughs on the rubbing surface, thereby serve as medium of treating the surface 27,116). Graphite nanomaterial was prepared and applied as additive in oil lubricating system, the result was so significant, but its preparation process was so challenging 13,112). The nanoscale modified graphene platelets (MGPs) if applied in lubricant operate as nano-bearings between tribocouples ${ }^{117)}$. According to ${ }^{118,119)}$, on synthesized $\mathrm{Al}$ ${ }_{2} \mathrm{O}_{3} / \mathrm{TiO}_{2}$ nanocomposite, gives good friction and wear properties on lubrication. Also observed that $\mathrm{Al}_{2} \mathrm{O}_{3} / \mathrm{TiO}_{2}$ enhanced the system tribological performance owing to the control on wear from the sliding friction to rolling effect during the operation ${ }^{107)}$. The mechanism theory identified two elements that contributed to the nanoparticles' outstanding performance. First, nanoparticles are normally spherical and operate as microbearings, preventing friction and carrying load between rubbing surfaces. As a result of the mechanism that controls lubrication, nanomaterials form tribo-film which help in preventing friction and wear ${ }^{120)}$.

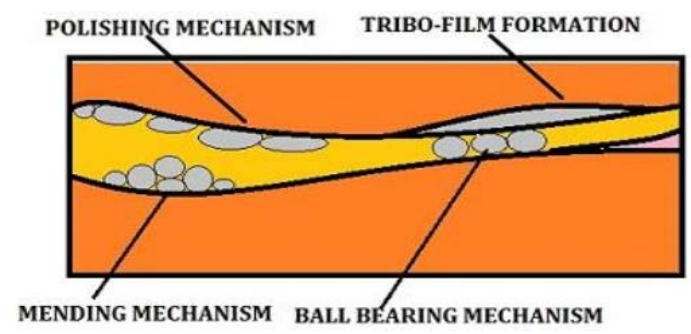

Fig. 15: Various lubrication mechanism of Nanoparticles ${ }^{30}$ 
(a)

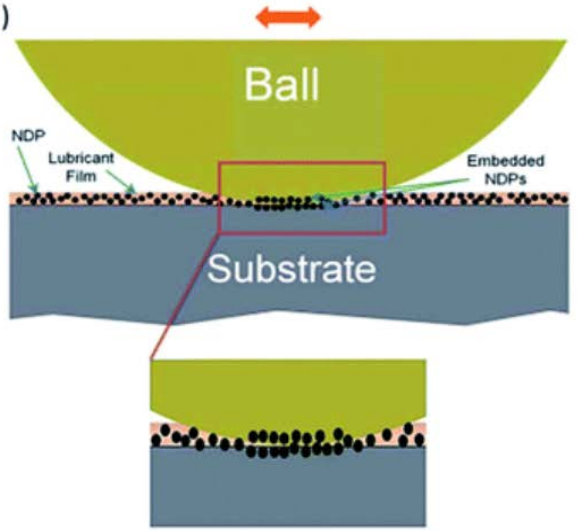

(b)

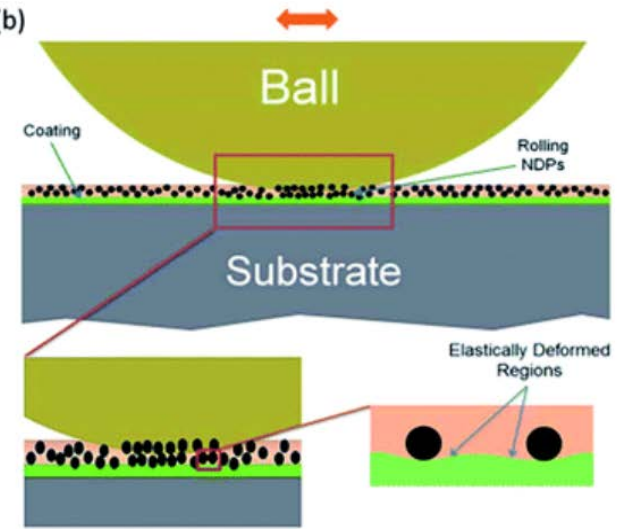

Fig. 16: Description on effects of NPs in the lubricant (a) bar and (b) coated stainless steel materials ${ }^{121)}$ 122)107)

\subsubsection{Protective film or Tribo film mechanism.}

In this particular mechanism, layer of amorphous from nanoparticles are formed on the sliding element surface, thereby reduce the actual area of contact. NPs can form sorbent (adsorption) films on the tribo-pair body surfaces, also NPs do undergo sintering by frictional pressure and heat and fill formed wear track ${ }^{78,107)}$. NPs that dispersed in fluid well are liable to form thin film on the operating metal surface, with the film of low shear and dense separate the contact thus reduces the friction manifestation. During the system operation, the NPs in the fluid tend to move to rubbing region due system inherited phenomenon. Demonstration on protective film mechanism was carried out by ${ }^{112)}$ employing magnesium borate in 500 -SN base oil. Result shows that amorphous film layer was formulated between the sliding contact surfaces. Because of the new layer formation, decrease in COF was recorded with increase in the wear resistance.

According to ${ }^{18,89)}$ reported that NPs in absent of oil lubricants can contribute in reducing friction and wear. Consequently, nanoparticles of nanocomposites like $\mathrm{SiO}_{2}$ tribological performance improves via material contacting surfaces from features of hydrophilic or hydrophobic to amphipathic 123,124). During NPs additive operation, agglomeration due help in rolling and sliding on the material contact area, tribo-par material hardness, pressure on the contact and interaction pull among the nanoparticles 120,125). In addition, at contact pressure around 1GPa, the tribo-pair works in the boundary lubrication regime via mechanically sheared, however, nanoparticles developed intermediate structure, adhere on the surface of the contact elements and create gap against interference ${ }^{17,120,126-128)}$ as see in Fig. 15 above. Investigation on IF-MoS ${ }_{2}$ NPs, prove that size and crystalline shape nature alter its lubricating properties ${ }^{129)}$. The coefficient of friction on inclusion of $1 \mathrm{w} \%$ of IF$\mathrm{MoS}_{2}$ under boundary lubrication decrease compared to pure PAO oil sample as shown in Fig. 17. Moreover, the COF performance in reduction properties does not cause by contact pressure ${ }^{18)}$. This tribo film mechanism is regarded as the most prevailing theory that give more insight about friction and wear reduction behavior of lubricant. In 130) study explain that heterogeneous dropping of NPs on element wearing surfaces due lead to transition of lubricant mechanism, forming traditional mixed lubrication to modified synergistic solution that promised with asperity.

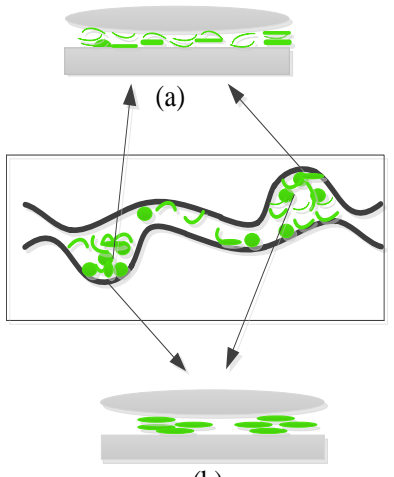

(b)
Model illustrating mechanism of NPs into valleys along the contacting surfaces with the valleys on the surface acts as reservoirs also control the NPs within the contact.

Fig. 17:Two mechanism of $\mathrm{MoS}_{2}$ protective tribofilms, (a) Monosheet that exfoliates with thin film formed and (b) Aggregates separating interfacial contact with thick film formed ${ }^{17)}$.

\subsubsection{Mending or self-repairing mechanism.}

When nanofluid is in operation, NPs in the lubricant tends to deposit as to fill and resurface the wounded rubbing contact through desorption and deposition and assisted in forming more smooth and flat pair ${ }^{131}$. This operation of self-repairing is mostly found with facecentered cubic soft metal. According to ${ }^{69)}$, reported that nano-copper additive in lubricant usually develop such feature thus separates the frictional materials during friction process. However, mending operation and selfrepairing mechanism is not limited to accumulation of NPs on material element surfaces but also size of NPs, melting points attributes. Explaining this, at severe temperature beyond the added materials, the NPs melts or sintered in the wounded contact area, symotheniously turn to filler and repair the element working surface ${ }^{27,699}$. Carbon nanotubes (CNTs) and Carbon nanofibers (CNFs) 
observed infiltrate of small gaps between rough surfaces in contact ${ }^{132)}$ thus, forming self-lubricating thin films as shown in Fig. 15 above. Another experimental work on polishing mechanism using fullerene nanoparticles together with refrigeration mineral oil was conducted by ${ }^{133)}$. observed that using diamond particles as nanoparticle additive in paraffin oil, smooth surface was found on the rubbing contact at the starting of the tribotest compared to surface image on pure paraffin oil ${ }^{133,134)}$.

\subsubsection{Polishing Mechanism or Effect.}

The mechanism depend on the hardness of the nanoparticles and contributes significantly in modifying or maintaining the machine surface element smooth ${ }^{96)}$. In this, the contacting region of the tribo pairs usually increased owing to the smoother nature of the material via the mechanism and increase the load bearing capacity with decrease in coefficient of friction 96,107,135). Investigation carried out by ${ }^{136}$ ), discovered that surface morphology of aluminium alloys 6061 material lubricated separately with commercial oil and nanofluid having $0.05 \%$ nano-diamond. Observed that the one lubricated with nanofluid decrease by $15 \%$ if compared with ordinary commercial oil. The result on the decrease on nanofluid type was because of polishing action of diamond nanoparticles leading to element smooth surface. On this operation, working element surface with much roughness, NPs do not function appropriate as to enhance the tribological properties of the nanofluids, thus found more active in tribo pair with low surface roughness. During investigation on mending mechanism under pin (H62 bronze) on disk (20CrMnTi steel) was analysed using SEM and STM ${ }^{69)}$. The work concluded that copper particles exhibit excellent mending mechanism in the element wear areas, supported by on same analysis conducted on sliding bearing using the internal combustion engine ${ }^{69,137)}$. Table 3 concisely give some base oil/additive report on their mechanism and tribological effect during operation.

Table.3: Summary of nano-additives in base oil (lubricant), effect on lubrication, mechanism and tribological properties

\begin{tabular}{|c|c|c|c|}
\hline $\begin{array}{l}\text { Base oil/nano } \\
\text { additive/function }\end{array}$ & $\begin{array}{l}\text { Mechanism (lubricant), surface } \\
\text { analysis methods }\end{array}$ & Tribological effect (friction and wear) & $\begin{array}{l}\text { Re } \\
\text { f. }\end{array}$ \\
\hline $\begin{array}{l}\mathrm{PAO} 10 / \mathrm{MoS}_{2}, \mathrm{BN} \\
{[\mathrm{FM}, \mathrm{AW}]}\end{array}$ & $\begin{array}{l}\text { Tribo-film formation } \\
\text { Raman spectroscopy }\end{array}$ & $\begin{array}{l}\text { Reduction in COF, improved friction and } \\
\text { wear reduction properties }\end{array}$ & 49,138-140) \\
\hline $\begin{array}{l}\mathrm{PAO} / \mathrm{MoS}_{2} . \\
{[\mathrm{AW}, \mathrm{EP}, \mathrm{FM}]}\end{array}$ & $\begin{array}{l}\text { Tribo-film formation } \\
\text { SEM, EDS }\end{array}$ & $\begin{array}{l}\text { Reduction in COF/Enhancement of } \\
\text { wear properties }\end{array}$ & 134) \\
\hline $\begin{array}{l}\mathrm{PAO} 6 / \mathrm{ZnO}, \mathrm{ZrO}_{2}, \mathrm{CaO} . \\
{[\mathrm{AW}, \mathrm{EP}]}\end{array}$ & $\begin{array}{l}\text { Mending effect } \\
\text { SEM, EDS }\end{array}$ & Improvement of Wear properties & 141) \\
\hline $\begin{array}{l}\text { SAE 15W40/h-BN. } \\
{[\mathrm{FM}, \mathrm{AW}]}\end{array}$ & $\begin{array}{l}\text { Rolling and Polishing effect } \\
\text { SEM }\end{array}$ & $\begin{array}{l}\text { Reduction in COF/enhancement of } \\
\text { wear properties }\end{array}$ & 101) \\
\hline $\begin{array}{l}\text { 500SN/WS2 } \\
{[\mathrm{EP}, \mathrm{AW}, \mathrm{FM}]}\end{array}$ & $\begin{array}{l}\text { Mending Effect and tribo-film } \\
\text { formation } \\
\text { XPS and SEM }\end{array}$ & $\begin{array}{l}\text { Reduction in COF/enhancement of } \\
\text { wear properties }\end{array}$ & 142) \\
\hline $\begin{array}{l}\text { Mineral Oil/CuO. } \\
\text { [FM, AW] }\end{array}$ & $\begin{array}{l}\text { Deposition, Polishing Effect } \\
\text { SEM, EDS }\end{array}$ & $\begin{array}{l}\text { Reduction in COF/enhancement of } \\
\text { wear properties }\end{array}$ & 143) \\
\hline $\begin{array}{l}\text { Palm TMP Ester/ } \\
\text { CuO,MoS2 } \\
{[\mathrm{AW}, \mathrm{EP}]}\end{array}$ & $\begin{array}{l}\text { Tribo-film formation and } \\
\text { Mending effect. } \\
\text { SEM, Raman spectroscopy }\end{array}$ & Enhancement of wear properties & 144) \\
\hline $\begin{array}{l}\text { Lubricating Oil } \\
\mathrm{ZnAl}_{2} \mathrm{O}_{4} \\
{[\mathrm{FM}, \mathrm{AW}]}\end{array}$ & $\begin{array}{l}\text { Mending Effect } \\
\text { SEM and EDS }\end{array}$ & $\begin{array}{l}\text { Reduction in COF/enhancement of } \\
\text { wear properties }\end{array}$ & 145) \\
\hline $\begin{array}{l}\text { Jatropha TMP } \\
\text { Ester/WS } 2 \\
{[\mathrm{AW}, \mathrm{EP}]}\end{array}$ & $\begin{array}{l}\text { Tribo-film formation. } \\
\text { SEM }\end{array}$ & Enhancement of wear properties & 146) \\
\hline $\begin{array}{l}\mathrm{PAO} 6 / \mathrm{ZnO}, \mathrm{ZrO}_{2}, \mathrm{CaO} / \\
{[\mathrm{AW}, \mathrm{EP}]}\end{array}$ & $\begin{array}{l}\text { Mending Effect } \\
\text { SEM and EDS }\end{array}$ & Enhancement of wear properties & 147) \\
\hline $\begin{array}{l}\text { Mineral Oil/ } \\
\text { ZnO. } \\
{[\mathrm{FM}, \mathrm{AW}]}\end{array}$ & $\begin{array}{l}\text { Tribo-film formation. } \\
\text { SEM and EDS }\end{array}$ & $\begin{array}{l}\text { Reduction in COF/enhancement of } \\
\text { wear properties }\end{array}$ & 143) \\
\hline
\end{tabular}




\begin{tabular}{|c|c|c|c|}
\hline $\begin{array}{l}\text { SE15W40/Al/Sn. } \\
{[\mathrm{AW}, \mathrm{EP}]}\end{array}$ & $\begin{array}{l}\text { Mending Effect } \\
\text { SEM and EDS }\end{array}$ & $\begin{array}{l}\text { Reduction in COF/enhancement of } \\
\text { wear properties }\end{array}$ & 148) \\
\hline $\begin{array}{l}\text { SAE-20W50/ } \\
\text { Carbon Nanoball. } \\
{[\mathrm{AW}]}\end{array}$ & $\begin{array}{l}\text { Mending Effect } \\
\text { SEM }\end{array}$ & Enhancement of wear properties & 149) \\
\hline $\begin{array}{l}\text { SAE-10/Fe, Cu, Co. } \\
{[\mathrm{FM}, \mathrm{AW}]}\end{array}$ & $\begin{array}{l}\text { Tribo-film formation. } \\
\text { SEM and EDS }\end{array}$ & $\begin{array}{l}\text { Reduction in COF/enhancement of } \\
\text { wear properties. }\end{array}$ & 73) \\
\hline $\begin{array}{l}\text { SAE-30/CuO. } \\
{[\mathrm{FM}, \mathrm{AW}]}\end{array}$ & $\begin{array}{l}\text { Mending and Ball bearing effect. } \\
\text { SEM and EDS }\end{array}$ & $\begin{array}{l}\text { Reduction in COF/enhancement of } \\
\text { wear properties. }\end{array}$ & $\begin{array}{l}\text { 150) } \\
151)\end{array}$ \\
\hline $\begin{array}{l}\text { Liquid Paraffin/ } \\
\text { Al/ } \\
{[\mathrm{FM}, \mathrm{AW}]}\end{array}$ & $\begin{array}{l}\text { Tribo-film formation. } \\
\text { SEM and EDS }\end{array}$ & $\begin{array}{l}\text { Reduction in COF/enhancement of } \\
\text { wear properties. }\end{array}$ & 152) \\
\hline $\begin{array}{l}\text { Super Gear/EP220/Gr. } \\
\text { [FM, AW]. }\end{array}$ & $\begin{array}{l}\text { Polishing Effects } \\
\text { SEM and EDS. }\end{array}$ & $\begin{array}{l}\text { Reduction in COF/enhancement of } \\
\text { wear properties. }\end{array}$ & 153) \\
\hline $\begin{array}{l}\text { PAO6/Ca. } \\
{[\mathrm{AW}, \mathrm{EP}]}\end{array}$ & $\begin{array}{l}\text { Tribo-film formation. } \\
\text { SEM and EDS }\end{array}$ & Enhancement of wear properties. & 154) \\
\hline $\begin{array}{l}\text { Liquid Paraffin/ } \\
\text { CuO. } \\
{[\text { FM, AW] }}\end{array}$ & $\begin{array}{l}\text { Ball bearing effect. } \\
\text { SEM and EDS }\end{array}$ & $\begin{array}{l}\text { Reduction in COF/enhancement of } \\
\text { wear properties. }\end{array}$ & 149) \\
\hline $\begin{array}{l}\text { TBA, Liquid } \\
\text { Paraffin/Pb. } \\
\text { [FM, AW] }\end{array}$ & $\begin{array}{l}\text { Ball bearing, Mending effect. } \\
\text { SEM and EDS }\end{array}$ & $\begin{array}{l}\text { Reduction in COF/enhancement of } \\
\text { wear properties. }\end{array}$ & 155) \\
\hline $\begin{array}{l}\text { Liquid Paraffin/ } \\
\mathrm{MoS}_{2}, \mathrm{TiO}_{2} . \\
{[\mathrm{FM}, \mathrm{AW}]}\end{array}$ & $\begin{array}{l}\text { Mending and tribo-film effect. } \\
\text { XPS }\end{array}$ & $\begin{array}{l}\text { Reduction in COF/enhancement of } \\
\text { wear properties. }\end{array}$ & 114) \\
\hline $\begin{array}{l}500 \text { SN Base Oil } \\
\mathrm{B}_{2} \mathrm{Mg}_{3} \mathrm{O}_{6} \\
{[\mathrm{FM}, \mathrm{AW}, \mathrm{EP}]}\end{array}$ & $\begin{array}{l}\text { Deposition, tribo-film formation } \\
\text { SEM and XPS }\end{array}$ & $\begin{array}{l}\text { Reduction in COF/enhancement of } \\
\text { wear properties }\end{array}$ & 144) \\
\hline $\begin{array}{l}\text { Sunflower oil/ZnO, } \mathrm{CuO} \\
\text { [FM and AW]. }\end{array}$ & $\begin{array}{l}\text { Tribo-film formation. } \\
\text { SEM. }\end{array}$ & $\begin{array}{l}\text { Reduction in COF/enhancement of } \\
\text { wear rate. }\end{array}$ & 143) \\
\hline $\begin{array}{l}\text { SAE10W-30/TiO2 } \\
\text { [FM, AW] }\end{array}$ & $\begin{array}{l}\text { Ball bearing effect. } \\
\text { SEM and EDS }\end{array}$ & $\begin{array}{l}\text { Reduction in COF/enhancement of } \\
\text { wear properties }\end{array}$ & $\begin{array}{l}\text { 114) } \\
156)\end{array}$ \\
\hline $\begin{array}{l}\text { Soyabean oil/ZnO,CuO. } \\
\text { [FM and AW] }\end{array}$ & $\begin{array}{l}\text { Tribo-film formation. } \\
\text { SEM }\end{array}$ & $\begin{array}{l}\text { Reduction in COF/enhancement of } \\
\text { wear rate. }\end{array}$ & 143) \\
\hline $\begin{array}{l}60 \text { SN Base Oil/ } \\
\mathrm{ZnO} . \\
{[\mathrm{FM}, \mathrm{AW}]}\end{array}$ & $\begin{array}{l}\text { Mending effect. } \\
\text { SEM }\end{array}$ & $\begin{array}{l}\text { Reduction in COF/enhancement of } \\
\text { wear properties }\end{array}$ & 157) \\
\hline
\end{tabular}

\subsection{Current Position of Nano-additives Globally}

Nano additives (nanoparticles) or lubricants oil additives are employed globally as a way of enhancing the lubricants tribological properties as well as their performances. The application of the additive is strictly base on its property/functional requirement. Current additives (nanoparticles) offers great reduction in waste of materials and elimination of use of harmful chemicals like cleaning solutions if compared to previously formulated additives ${ }^{5,15}$ ). In order make the new technology more unique, selected additives are prepared into packages and recommended/labelled for specific base oil for a particular application. This guide is mostly found in the internal combustion engine application. The utilization of these nano-additives can also be found in other areas like gear box oil additives, machining and coolant additives, hydraulic fluid additives and in the metal working lubricants additives. following the current world 
sustainability, opportunities has opened from consumption of most of neglected raw materials which turn to be of great contribution in actualizing the nanoadditives products. In addition, huge achievement had been recorded from biomaterials toward nanomaterials/additive formulation as they possess similar properties to fossil feedstock 158,159). The operations perform by these nano-additives depend on the type which include; anti-wear, detergents, extreme pressure, dispersants, viscosity index improver and oxidation inhibitors. Through provision of the various lubricant properties, nano-additives will boost production productivity by reducing friction and power losses in our industries, notably in tribology applications such as base oil, direct lubricants, and grease. Carbon base nanotubes, fullerenes, metal oxides, polymers, ceramics, and composites are the most revealing types of nano-additives. Based on current technology, most machines operate for long periods of time with high loads, necessitating the use of a sufficient additive to regulate severe pressure and prevent wear. Inorganic fullerenes (IF) possess such property and exhibits rolling mechanism, capable of

\subsection{Summary and Future Scope}

On account of their morphology and mechanisms, NPs have shown enormous potential that is predominantly use in lubrication. In the past decade, researchers have explored different ideas and formulations to enhance tribological properties of lubricants including material elements selection, modifications in design geometry and formulation of various forms of additives. Recently, the effect of NP additives performance in improving tribological properties of lubricating oil (base oil and additives) has attracted researcher's attention. Inability of NPs to form homogeneous mixture with lubricating oil (equilibrium of NPs in solution) due to insufficient dispersion agent could lead to agglomeration and may affect the lubricant performance. Our current state of knowledge on keeping lubricating oil (with NPs) enhanced for tribological application is briefly summarized as follows

i. Reduction in COF and enhancement of wear properties can achieve through NPs additives with excellent thermal conductivity for stabilization of formulated film and surface topography smoothening.

ii. Viscosity increasing effect with decrease in coefficient of friction due achieved from NPs

\section{References}

1) M.K.A. Ali, and H. Xianjun, "Improving the tribological behavior of internal combustion engines resisting the wear effects when blended with base oil and grease but the application is still limited in the field. Nanoadditive anti-wear mechanism works by depositing nanoparticles in the worn surface's valley, which improves tribological characteristics by lowering boundary friction.

Metal oxides are commonly used in engine oil, metalworking fluids, and a variety of other applications due to their anti-wear and extreme pressure characteristics. They are currently being pushed higher in the global market to replace common ZDDP and Sulphur phosphorous due to their negative environmental impact. (hazardous emission) ${ }^{160}$ ). On the other hand, products of carbon based additives and nano-diamond showcase some excellent properties during lubrication like performing almost all the four lubrication mechanism with good wear and friction resistance. Organic products (biomaterials) of nano-additives yield another opportunity in achieving sustainability goal due to their eco-friendly characteristics and good properties including thermal strength. The recorded results on nano-additives evidently provide solution to the unwanted occurrences during lubrication and stands as promising among every class of additives.

additive with high temperature stability, capable to enhance strength, stiffness and resistance to wear. iii. Carbon nanotubes (MWCNT, DWCNT and SWCNT) dispersed with surfactant reduces wear, lower frictional force, Improve anti-scuffing performance with significant reduction in friction.

Although presence of NPs additives may facilitate film formation, enhanced wear properties and load carrying capacity, however, operation on high load for long operating hours is still facing many challenges. As lubrication is associated with various mechanisms, and difficult to understand due to many NPs with different operation for different applications. Another future studies should be directed toward organic biodegradable Nanoadditives, chemically modified and hybridized for tribological application. Formulation of new modified nano additives could yield improved mechanism and performance properties which influences the tribological behavior of lubricants.

\section{Acknowledgement}

The authors hereby acknowledge the research grants provided by Universiti Teknologi Malaysia, under GUP project no. Q. J130000.2524.20H29 and FRGS project no. R. J130000.7951.5F057

via the addition of nanoparticles to engine oils," Nanotechnol. Rev., 4 (4) 347-358 (2015). doi:10.1515/ntrev-2015-0031.

2) M.K.A. Ali, H. Xianjun, L. Mai, C. Qingping, R.F. Turkson, and C. Bicheng, "Improving the tribological 
characteristics of piston ring assembly in automotive engines using al2o3 and tio2 nanomaterials as nanolubricant additives,” Tribol. Int., 103 540-554 (2016). doi:10.1016/j.triboint.2016.08.011.

3) S. Shahnazar, S. Bagheri, and S.B. Abd Hamid, "Enhancing lubricant properties by nanoparticle additives,” Int. J. Hydrogen Energy, 41 (4) 31533170 (2016). doi:10.1016/j.ijhydene.2015.12.040.

4) G W Stachowiak; A W Batchelor, "Engineering tribology: Tribological Technology and Engineeringmechanical,” 2014.

5) I. Khan, K. Saeed, and I. Khan, "Nanoparticles: properties, applications and toxicities," Arab. J. Chem., $12 \quad$ (7) 908-931 (2019). doi:10.1016/j.arabjc.2017.05.011.

6) S.C. Tung, and M.L. McMillan, “Automotive tribology overview of current advances and challenges for the future,” Tribol. Int., 37 (7) 517-536 (2004). doi:10.1016/j.triboint.2004.01.013.

7) P. Olander, "Tribology for Greener Combustion Engines,” in: Digit. Compr. Summ. Uppsala Diss. from Fac. Sci. Technol., 2018: p. 1607.

8) K. Holmberg, R. Siilasto, T. Laitinen, P. Andersson, and A. Jäsberg, "Global energy consumption due to friction in paper machines,” Tribol. Int., 62 58-77 (2013). doi:10.1016/j.triboint.2013.02.003.

9) L. Kong, J. Sun, and Y. Bao, "Preparation, characterization and tribological mechanism of nanofluids,” RSC Adv., 7 (21) 12599-12609 (2017). doi:10.1039/c6ra28243a.

10) S. Ghalme, and Y.J. Bhalerao, "Application of nanoparticles as additive for lubricant nano-materials in tribology,” Recent Patents Mater. Sci., 10 (2) 8896

doi:10.2174/1874464810666180329143917.

(2017).

11) V.W. Wong, and S.C. Tung, "Overview of automotive engine friction and reduction trends-effects of surface, material, and lubricant-additive technologies," Friction, 4 (1) 1-17 (2016). doi:10.1007/s40544-016-0107-9.

12) R.D. Britton, C.D. Elcoate, M.P. Alanou, H.P. Evans, and R.W. Snidle, "Effect of surface finish on gear tooth friction,” J. Tribol., 122 (1) 354-360 (2000). doi:10.1115/1.555367.

13) M.K.A. Ali, H. Xianjun, M.A.A. Abdelkareem, M. Gulzar, and A.H. Elsheikh, "Novel approach of the graphene nanolubricant for energy saving via antifriction/wear in automobile engines,” Tribol. Int., 124 209-229 (2018). doi:10.1016/j.triboint.2018.04.004.

14) A. Matthews, S. Franklin, and K. Holmberg, "Tribological coatings: contact mechanisms and selection,” J. Phys. D. Appl. Phys., 40 (18) 54635475 (2007). doi:10.1088/0022-3727/40/18/S07.

15) O.S. Ivanova, C.B. Williams, and T.A. Campbell, "Additive manufacturing (am) and nanotechnology: promises and challenges,” Rapid Prototyp. J., 19 (5) 1355-2546 (2013). doi:10.1108/RPJ-12-2011- 0127/full/html.

16) R.Z. M. Gulzar*, H.H Masjuki*, M.A Kalam, M. Varman, NWM Zulkifli, R.A. Mufti, “Tribological performance of nanoparticles as lubricating oil additives," Cent. Energy Sci. Dep. Mech. Eng. Fac. Eng. Univ. Malaya, Kuala Lumpur, Malaysia., 1-47 (2016).

17) M. Kalin, J. Kogovšek, and M. Remškar, "Mechanisms and improvements in the friction and wear behavior using mos 2 nanotubes as potential oil additives,” Wear, 280-281 (127) 36-45 (2012). doi:10.1016/j.wear.2012.01.011.

18) H. Ghaednia, and R.L. Jackson, "The role of nanoparticles in lubricants; performing lubricated and dry friction tests,” Tribol. Lubr. Technol., 71 (7) 2024 (2015).

19)I. Minami, "Molecular science of lubricant additives," Appl. Sci., 7 (5) 445 (2017). doi:10.3390/app7050445.

20) M. Upadhyay, G. Karmakar, G.S. Kapur, and P. Ghosh, "Multifunctional greener additives for lubricating oil,” Polym. Eng. Sci., 58 (5) 810-815 (2017). doi:10.1002/pen.24635.

21) I. Ijaz, E. Gilani, A. Nazir, and A. Bukhari, "Detail review on chemical, physical and green synthesis, classification, characterizations and applications of nanoparticles,” Green Chem. Lett. Rev., 13 (3) 59-81 (2020). doi:10.1080/17518253.2020.1802517.

22) S. Hernandez, "Friction and wear phenomena in steels at elevated temperatures: Luleå University of Technology Department of Engineering Sciences and Mathematics Division of Machine Elements,” 2016. www.ltu.se.

23) N. Martain, J., and Ohmae, "Nanolubricants and additives. john wiley and sons ltd.,” Lubricants, 2 (2) 44-65 (2008). doi:10.3390/lubricants2020044.

24) N. Alwadani, and P. Fatehi, "Synthetic and ligninbased surfactants: challenges and opportunities," Carbon Resour. Convers., 1 (2) 126-138 (2018). doi:10.1016/j.crcon.2018.07.006.

25) A T C, "Lubricant Additives: Use and Benefits," in: Tech. Comm. Pet. Addit. Manuf. Eur., 2016: p. 64. https://www.atc-europe.org/public/Document 118 Lubricant Additives Use and Benefits.pdf.

26) C.H. Bovington, "Friction, wear and the role of additives in controlling them," Chem. Technol. Lubr., 7 (3) 77-105 (2010). doi:10.1023/b105569_3.

27) B. Wang, Z. Zhong, H. Qiu, D. Chen, W. Li, S. Li, and X. Tu, "Nano serpentine powders as lubricant additive: tribological behaviors and self-repairing performance on worn surface,” Nanomaterials, 10 (5) 1-11 (2020). doi:10.3390/nano10050922.

28) K.K. Mistry, A. Morina, A. Erdemir, and A. Neville, "Extreme pressure lubricant additives interacting on the surface of steel- and tungsten carbide-doped diamond-like carbon,” Tribol. Trans., 56 (4) 623-629 (2013). doi:10.1080/10402004.2013.771415.

29) W.-M.L. Xiao-bo Wang, "Nanoparticle-based 
lubricant additives,” Encycl. Tribol., (Liu 2003) 1-18 (2017).

30) W.K. Shafi, A. Raina, and M.I. Ul Haq, "Friction and wear characteristics of vegetable oils using nanoparticles for sustainable lubrication," Tribol. Mater. Surfaces Interfaces, 12 (1) 27-43 (2018). doi:10.1080/17515831.2018.1435343.

31) P. Rabaso, F. Ville, F. Dassenoy, M. Diaby, P. Afanasiev, J. Cavoret, B. Vacher, and T. Le Mogne, "Boundary lubrication: influence of the size and structure of inorganic fullerene-like mos2 nanoparticles on friction and wear reduction," Wear, $320 \quad$ (1) 161-178 doi:10.1016/j.wear.2014.09.001.

32) A. Kotia, K. Chowdary, I. Srivastava, S.K. Ghosh, and M.K.A. Ali, "Carbon nanomaterials as friction modifiers in automotive engines: recent progress and perspectives," J. Mol. Liq., 310 1-39 (2020). doi:10.1016/j.molliq.2020.113200.

33) H. Spikes, "Friction modifier additives," Tribol. Lett., 60 (1) 1-26 (2015). doi:10.1007/s11249-015-0589-z.

34) R. Feynman, "There's plenty of room at the bottom. engineering and science and science," Sci. Res., 03 (23) 22-36 (1960). doi:10.4236/sm.2013.31012.

35) A. Rajak, "Nanotechnology and its application," Nanomedicine Nanotechnol., 9 (3) 100-502 (2018). doi:10.4172/2157-7439.1000502.

36) X. Fang, J. Liu, and V. Gupta, "Fundamental formulations and recent achievements in piezoelectric nano-structures: a review," Nanoscale, (5) 1-5 (2013).

37) N.G.\& D.L. Jonathan E. Spowart, "Additive manufacturing of composites and complex materials," J. Mater. Chem., 70 (9) 272-274 (2018).

38) al. Chang-Gun Lee1, Yu-Jin Hwang et, “A study on the tribological characteristics of graphite nano lubricants,” Int. J. Precis. Eng. Manuf., 10 (1) 85-129 (2009). doi:10.1115/1.4023080.

39) J.E. Lee, N. Lee, T. Kim, J. Kim, and T. Hyeon, "Multifunctional mesoporous silica nanocomposite nanoparticles for theranostic applications," Acc. Chem. Res., $44 \quad$ (10) 893-902 (2011). doi:10.1021/ar2000259.

40) O. Zaytseva, and G. Neumann, "Carbon nanomaterials: production, impact on plant development, agricultural and environmental applications,” Chem. Biol. Technol. Agric., 3 (1) 1-85 (2016). doi:10.1186/s40538-016-0070-8.

41) M. Benelmekki, and M. Benelmekki, "An introduction to nanoparticles and nanotechnology," Des. Hybrid Nanoparticles, (April 2015) 1-21 (2014). doi:10.1088/978-1-6270-5469-0ch1.

42) M. Gulzar et al., "Improving the aw / ep ability of chemically modified palm oil by adding cuo and mos 2 nanoparticles,” Tribol. Int., 88 (8) 271-279 (2015).

43) J. Zhu, H. Bi, Y. Wang, X. Wang, X. Yang, and L. Lu, "CuO nanocrystals with controllable shapes grown from solution without any surfactants,” Mater. Chem.
Phys., $109 \quad$ (1) 34-38 (2008).

doi:10.1016/j.matchemphys.2007.10.027.

44) K.J. Carroll, D.M. Hudgins, S. Spurgeon, K.M. Kemner, B. Mishra, M.I. Boyanov, L.W. Brown, M.L. Taheri, and E.E. Carpenter, "One-pot aqueous synthesis of fe and ag core/shell nanoparticles,” Chem. Mater., $22 \quad$ (23) 6291-6296 (2010). doi:10.1021/cm101996u.

45) Y. Shin, J.M. Blackwood, I.T. Bae, B.W. Arey, and G.J. Exarhos, "Synthesis and stabilization of selenium nanoparticles on cellulose nanocrystal," Mater. Lett., $61 \quad$ (21) 4297-4300 (2007). doi:10.1016/j.matlet.2007.01.091.

46) M. Benelmekki, and M. Benelmekki, "Design of ternary magneto-plasmonic nanoparticles," Des. Hybrid Nanoparticles, 8 (11) 1-14 (2014). doi:10.1088/978-1-6270-5469-0ch4.

47) Y. Liu, J. Luo, Y. Shin, S. Moldovan, O. Ersen, A. Hébraud, G. Schlatter, C. Pham-Huu, and C. Meny, "Sampling the structure and chemical order in assemblies of ferromagnetic nanoparticles by nuclear magnetic resonance,” Nat. Commun., 7 (2016). doi:10.1038/ncomms11532.

48) L. Joly-Pottuz, B. Vacher, N. Ohmae, J.M. Martin, and T. Epicier, "Anti-wear and friction reducing mechanisms of carbon nano-onions as lubricant additives,” Tribol. Lett., 30 (1) 69-80 (2008). doi:10.1007/s11249-008-9316-3.

49) N.G. Demas, E. V. Timofeeva, J.L. Routbort, and G.R. Fenske, "Tribological effects of bn and mos2 nanoparticles added to polyalphaolefin oil in piston skirt/cylinder liner tests,” Am. Soc. Mech. Eng. Tribol. Div. TRIB, $47 \quad$ (3) 91-102 (2012). doi:10.1115/IJTC2012-61062.

50) H. Ghaednia, M.S. Hossain, and R.L. Jackson, "Tribological performance of silver nanoparticleenhanced polyethylene glycol lubricants," Tribol. Trans., $59 \quad$ (4) 585-592 (2016). doi:10.1080/10402004.2015.1092623.

51) Z. Liu, J. Li, G. Knothe, B.K. Sharma, and J. Jiang, "Improvement of diesel lubricity by chemically modified tung-oil-based fatty acid esters as additives," Energy and Fuels, 33 (6) 5110-5115 (2019). doi:10.1021/acs.energyfuels.9b00854.

52) M. Salavati-Niasari, F. Davar, and N. Mir, "Synthesis and characterization of metallic copper nanoparticles via thermal decomposition,” Polyhedron, 27 (17) 3514-3518 (2008). doi:10.1016/j.poly.2008.08.020.

53) a L.T. and J.Q. Chang Liu, a Bin Qian, *b Xiaofeng Liu, “Additive manufacturing of silica glass using laser stereolithography with a top-down approach and fast debinding," RSC Adv., 6 (29) 1-12 (2018). doi:10.1039/C5RA06853C.

54) C. Di Li, B. Li, Y. Shen, M. Jin, and J.J. Xu, "Effect of surface chemical etching on the lubricated reciprocating wear of honed al-si alloy,” J. Eng. Tribol., $232 \quad$ (6) 722-731 (2018). doi:10.1177/1350650117727213. 
55) P. Shah, and A. Gavrin, "Synthesis of nanoparticles using high-pressure sputtering for magnetic domain imaging," J. Magn. Magn. Mater., 301 (1) 118-123 (2006). doi:10.1016/j.jmmm.2005.06.023.

56) E. Lugscheider, S. Bärwulf, C. Barimani, M. Riester, and H. Hilgers, "Magnetron-sputtered hard material coatings on thermoplastic polymers for clean room applications," Surf. Coatings Technol., 108-109 398402 (1998). doi:10.1016/S0257-8972(98)00627-6.

57) M.M. Vincenzo Amendola, "Laser ablation synthesis in solution and size manipulation of noble metal nanoparticles,” Phys. Chem. Chem. Phys., 11 38053821 (2009). doi:10.1039/).

58) S. Crivellaro, A. Guadagnini, D.M. Arboleda, D. Schinca, and V. Amendola, "A system for the synthesis of nanoparticles by laser ablation in liquid that is remotely controlled with pc or smartphone," Rev. Sci. Instrum., 90 (3) 1-10 (2019). doi:10.1063/1.5083811.

59) H.M.M. Ibrahim, "Green synthesis and characterization of silver nanoparticles using banana peel extract and their antimicrobial activity against representative microorganisms," J. Radiat. Res. Appl. Sci., $8 \quad$ (3) 265-275 doi:10.1016/j.jrras.2015.01.007.

60) L.C. Varanda, C.G.S. Souza, D.A. Moraes, H.R. Neves, J.B. Souza Junior, M.F. Silva, R.A. Bini, R.F. Albers, T.L. Silva, and W. Beck, "Size and shapecontrolled nanomaterials based on modified polyol and thermal decomposition approaches. A brief review,” 2019. doi:10.1590/00013765201920181180.

61) C.P. and M.F. V. Zin, S. Barison, F. Agresti, a L. Colla, "Improved tribological and thermal properties of lubricants by graphene based nano- additives," RSC Adv., 5 (64) 1-21 (2016). doi:10.1039/c3ra23409f.

62) J. Antonio Cecilia, Daniel Ballesteros Plata,Rosana Maria et. al, "An overview of the biolubricant production process: challenges and future perspectives," Environ. Catal. Process. Based Biomass, 8 (3) 257 (2020).

63) R. Chou, A.H. Battez, J.J. Cabello, J.L. Viesca, A. Osorio, and A. Sagastume, "Tribological behavior of polyalphaolefin with the addition of nickel nanoparticles,” Tribol. Int., 43 (12) 2327-2332 (2010). doi:10.1016/j.triboint.2010.08.006.

64) J.M.L. Del Río, E.R. López, M.G. Gómez, S.Y. Vilar, Y. Piñeiro, J. Rivas, D.E.P. Gonçalves, J.H.O. Seabra, and J. Fernández, "Tribological behavior of nanolubricants based on coated magnetic nanoparticles and trimethylolpropane trioleate base oil,” Nanomaterials, $10 \quad$ (4) (2020). doi:10.3390/nano10040683.

65) J. Jeevanandam, A. Barhoum, Y.S. Chan, A. Dufresne, and M.K. Danquah, "Review on nanoparticles and nanostructured materials : history, sources, toxicity and regulations,” J. Nanotechnol., 9 (3) 1050-1074
(2018).

66) M. Tohyama, T. Ohmori, A. Murase, and M. Masuko, "Friction reducing effect of multiply adsorptive organic polymer,” Tribol. Int., 42 (6) 926-933 (2009). doi:10.1016/j.triboint.2008.12.012.

67) S.C. Shi, "Tribological performance of green lubricant enhanced by sulfidation if-mos2,” Materials (Basel)., 9 (10) 1-8 (2016). doi:10.3390/ma9100856.

68) L.R. Rudnick, "Lubricant additives: Chemistry and Applications, Second Edition,” 2009.

69) G. Liu, X. Li, B. Qin, D. Xing, Y. Guo, and R. Fan, "Investigation of the mending effect and mechanism of copper nano-particles on a tribologically stressed surface," Tribol. Lett., 17 (4) 961-966 (2004). doi:10.1007/s11249-004-8109-6.

70) H.L. Yu, Y. Xu, P.J. Shi, B.S. Xu, X.L. Wang, Q. Liu, and H.M. Wang, "Characterization and nanomechanical properties of tribofilms using $\mathrm{cu}$ nanoparticles as additives," Surf. Coatings Technol., $203 \quad$ (1-2) 28-34 (2008). doi:10.1016/j.surfcoat.2008.07.032.

71) L. Gara, and Q. Zou, "Friction and wear characteristics of water-based zno and al 2o 3 nanofluids,” Tribol. Trans., 55 (3) 345-350 (2012). doi:10.1080/10402004.2012.656879.

72) P.D. Srivyas, and M.S. Charoo, "A review on tribological characterization of lubricants with nano additives for automotive applications," Tribol. Ind., $40 \quad$ (4) 594-623 (2018). doi:10.24874/ti.2018.40.04.08.

73) J. Padgurskas, R. Rukuiza, I. Prosyčevas, and R. Kreivaitis, "Tribological properties of lubricant additives of fe, cu and co nanoparticles,” Tribol. Int., 60 224-232 (2013). doi:10.1016/j.triboint.2012.10.024.

74) B. Sen Zhang, B.S. Xu, Y. Xu, F. Gao, P.J. Shi, and Y.X. Wu, "CU nanoparticles effect on the tribological properties of hydrosilicate powders as lubricant additive for steelsteel contacts,” Tribol. Int., 44 (7-8) 878-886 (2011). doi:10.1016/j.triboint.2011.03.002.

75) A.C. Opia, A. Hamid, M. Kameil, S. Syahrullail, C. Mamah, M.I. Izmi, C. Daud, Z. Hilmi, A. Rahim, and A. Bakar, "Tribological behavior of organic formulated polymer concentration effect in bio-based lubricant using high-frequency reciprocating rig," $J$. Teknol., 30 (June) 44-60 (2021).

76) C.Y. Tai, C. Te Tai, M.H. Chang, and H.S. Liu, "Synthesis of magnesium hydroxide and oxide nanoparticles using a spinning disk reactor," Ind. Eng. Chem. Res., $46 \quad$ (17) 5536-5541 (2007). doi:10.1021/ie060869b.

77) S. Samion, Mohd Izhan Ibrahim, Nor Azwadi Che Sidik, "Wear behavior of titanium alloy lubricated with palm,” UTM J. Teknol., 66 (1) 112-123 (2012).

78) X. Li, M. Murashima, and N. Umehara, "Effect of nanoparticles as lubricant additives on friction and wear behavior of tetrahedral amorphous carbon ( ta- 
c ) coating,” J. Tribol., 16 (June 2017) 15-29 (2018).

79) W. Sigmund, J. Yuh, H. Park, V. Maneeratana, G. Pyrgiotakis, A. Daga, J. Taylor, and J.C. Nino, "Processing and structure relationships in electrospinning of ceramic fiber systems," J. Am. Ceram. Soc., $89 \quad$ (2) 395-407 (2006). doi:10.1111/j.1551-2916.2005.00807.x.

80) M. Ding, B. Lin, T. Sui, A. Wang, S. Yan, and Q. Yang, "The excellent anti-wear and friction reduction properties of silica nanoparticles as ceramic water lubrication additives,” Ceram. Int., 44 (12) 1490114906 (2018). doi:10.1016/j.ceramint.2018.04.206.

81) Q. Zhu, Y. Pan, X. Jia, J. Li, M. Zhang, and L. Yin, "Review on the stability mechanism and application of water-in-oil emulsions encapsulating various additives,” Compr. Rev. Food Sci. Food Saf., 18 (6) 1660-1675 (2019). doi:10.1111/1541-4337.12482.

82) S.I. Shara, E.A. Eissa, and J.S. Basta, "Polymers additive for improving the flow properties of lubricating oil,” Egypt. J. Pet., 27 (4) 795-799 (2018). doi:10.1016/j.ejpe.2017.12.001.

83) P. Wang, N. Cui, J. Luo, H. Zhang, H. Guo, P. Wen, and F. Ren, "Stable water-in-oil emulsions formulated with polyglycerol polyricinoleate and glucono- $\delta$ lactone-induced casein gels,” Food Hydrocoll., 57 217-220 (2016). doi:10.1016/j.foodhyd.2016.01.013.

84) J.M. González, F. Quintero, J.E. Arellano, R.L. Márquez, C. Sánchez, and D. Pernía, "Effects of interactions between solids and surfactants on the tribological properties of water-based drilling fluids," Colloids Surfaces A Physicochem. Eng. Asp., 391 (13) 216-223

(2011). doi:10.1016/j.colsurfa.2011.04.034.

85) S. Bhaviripudi, E. Mile, S.A. Steiner, A.T. Zare, M.S. Dresselhaus, A.M. Belcher, and J. Kong, "CVD synthesis of single-walled carbon nanotubes from gold nanoparticle catalysts,” J. Am. Chem. Soc., 129 (6) 1516-1517 (2007). doi:10.1021/ja0673332.

86) S. Nasir, M.Z. Hussein, Z. Zainal, and N.A. Yusof, "Carbon-based nanomaterials/allotropes: a glimpse of their synthesis, properties and some applications," Materials (Basel)., $11 \quad$ (2) 1-24 (2018). doi:10.3390/ma11020295.

87) M. Duraia, and A. Hannora, "Direct growth of carbon nanotubes on hydroxyapatite using mpecvd," 1 (132) 1-13 (2012).

88) A.C. Opia, A. Hamid, M. Kameil, S. Syahrullail, and S.C. Mamah, "Effect of concentration on the tribological behavior of cyclic heated formulated organic carbon nanotubes in base lubricant under boundary conditions,” Tribol. Online, 16 (4) 199-209 (2021).

89) Z. Zhang, J. Liu, T. Wu, and Y. Xie, "Effect of carbon nanotubes on friction and wear of a piston ring and cylinder liner system under dry and lubricated conditions," Friction, 5 (2) 147-154 (2017). doi:10.1007/s40544-016-0126-6.

90) P.L. Dickrell, S.K. Pal, G.R. Bourne, C. Muratore,
A.A. Voevodin, P.M. Ajayan, L.S. Schadler, and W.G. Sawyer, "Tunable friction behavior of oriented carbon nanotube films,” Tribol. Lett., 24 (1) 85-90 (2006). doi:10.1007/s11249-006-9162-0.

91) K. Vyavhare, and P.B. Aswath, "Tribological properties of novel multi-walled carbon nanotubes and phosphorus containing ionic liquid hybrids in grease,” Front. Mech. Eng., 5 (1) 1-22 (2019). doi:10.3389/fmech.2019.00015.

92) S.S.N. Azman, N.W.M. Zulkifli, H. Masjuki, M. Gulzar, and R. Zahid, "Study of tribological properties of lubricating oil blend added with graphene nanoplatelets," J. Mater. Res., 31 (13) 1932-1938 (2016). doi:10.1557/jmr.2016.24.

93) A. Mohamed, "Synthesis , characterization , and applications carbon nanofibers,” J. Nanomater., (1) 243-257 (2019).

94) W. Österle, and A.I. Dmitriev, "The role of solid lubricants for brake friction materials," Lubricants, 4 (1) 1-12 (2016). doi:10.3390/lubricants4010005.

95) K.P. Lijesh, S.M. Muzakkir, and H. Hirani, "Experimental tribological performance evaluation of nano lubricant using multi-walled carbon nano-tubes (mwcnt),” Int. J. Appl. Eng. Res., 10 (6) 14543-14550 (2015).

96) X. Tao, Z. Jiazheng, and X. Kang, "The ball-bearing effect of diamond nanoparticles as an oil additive," $J$. Phys. D. Appl. Phys., 29 (11) 2932-2937 (1996). doi:10.1088/0022-3727/29/11/029.

97) C.C. Filip Ilie, “Tribological properties of the lubricant containing titanium dioxide nanoparticles as an additive,” Lubricants, 4 (2) 2-18 (2016).

98) H.Y. Chu, W.C. Hsu, and J.F. Lin, “The anti-scuffing performance of diamond nano-particles as an oil additive," Wear, 268 (7-8) 960-967 (2010). doi:10.1016/j.wear.2009.12.023.

99) C.C. Chou, and S.H. Lee, "Rheological behavior and tribological performance of a nanodiamond-dispersed lubricant," J. Mater. Process. Technol., 201 (1-3) 542-547 doi:10.1016/j.jmatprotec.2007.11.169.

100) L. Kong, H. Hu, T. Wang, D. Huang, and J. Fu, "Synthesis and surface modification of the nanoscale cerium borate as lubricant additive,” J. Rare Earths, 29 (11) 1095-1099 (2011). doi:10.1016/S10020721(10)60605-9.

101) M.I.H.C. Abdullah, M.F. Bin Abdollah, H. Amiruddin, N. Tamaldin, and N.R.M. Nuri, "Optimization of tribological performance of hbn/al2o3 nanoparticles as engine oil additives," Procedia Eng., $68 \quad 313-319 \quad$ (2013). doi:10.1016/j.proeng.2013.12.185.

102) M. Shen, J. Luo, and S. Wen, "The tribological properties of oils added with diamond nano-particles," Tribol. Trans., $44 \quad$ (3) 494-498 (2001). doi:10.1080/10402000108982487.

103) A. Ghazaly, B. Seif, and H.G. Salem, "Mechanical and tribological properties of aa2124- 
graphene self lubricating nanocomposite,” Miner. Met. Mater. Ser., (210869) 411-415 (2016). doi:10.1007/978-3-319-65136-1_71.

104) K. Rajkumar, and S. Aravindan, “Tribological behavior of microwave processed coppernanographite composites,” Tribol. Int., 57 282-296 (2013). doi:10.1016/j.triboint.2012.06.023.

105) M.M.H. Bastwros, A.M.K. Esawi, and A. Wifi, "Friction and wear behavior of al-cnt composites," Wear, $307 \quad(1-2) \quad 164-173 \quad$ (2013). doi:10.1016/j.wear.2013.08.021.

106) D.L.C. Sohail M. A. K. Mohammed, "Carbon nanotube reinforced aluminum matrix composites," Carbon Nanotub. Nanocomposite Res., 22 (4) 27-38 (2019).

107) K. Lee, Y. Hwang, S. Cheong, Y. Choi, L. Kwon, J. Lee, and S.H. Kim, "Understanding the role of nanoparticles in nano-oil lubrication,” Tribol. Lett., 35 (2) 127-131 (2009). doi:10.1007/s11249-0099441-7.

108) M.K.A. Ali, and H. Xianjun, "Improving the heat transfer capability and thermal stability of vehicle engine oils using al2o3/tio2 nanomaterials," Powder Technol., $363 \quad 48-58 \quad$ (2020). doi:10.1016/j.powtec.2019.12.051.

109) W.L.\& Q.X. Li, B, X. Wang, “Tribochemistry and antiwear mechanism of organic - inorganic nanoparticles as lubricant additives,” 22 79-84 (2006).

110) R.Y. N.W.M. Zulkifli , M.A. Kalama, H.H. Masjukia, "Experimental analysis of tribological properties of biolubricant with nanoparticle additive," in: Malaysian Int. Tribol. Conf., 2013: pp. 152-157.

111) F. Chinas-Castillo, and H.A. Spikes, "Mechanism of action of colloidal solid dispersions," J. Tribol., $125 \quad$ (3) 552-557 (2003). doi:10.1115/1.1537752.

112) Z.S. Hu, R. Lai, F. Lou, L.G. Wang, Z.L. Chen, G.X. Chen, and J.X. Dong, "Preparation and tribological properties of nanometer magnesium borate as lubricating oil additive," Wear, 252 (5-6) 370-374 (2002). doi:10.1016/S00431648(01)00862-6.

113) R.B. Rastogi, M. Yadav, and A. Bhattacharya, "Application of molybdenum complexes of 1-aryl2,5-dithiohydrazodicarbonamides as extreme pressure lubricant additives," Wear, 252 (9-10) 686692 (2002). doi:10.1016/S0043-1648(01)00878-X.

114) S.S.U. Ingole, Sudeep, Archana Charanpahari, Amol Kakade, "Tribological behavior of nano tio2 as an additive in base oil," Wear, 301 (1-2) 776-785 (2019).

115) S. Peng, D., Kang, Y., Chen, C. and Chen Fuchun Shu, "The tribological behavior of modi ed diamond nanoparticles in liquid paraffin," Ind. Lubr. Tribol., $16 \quad$ (4) 213-219 (2009). doi:10.1108/00368790910960057/full/html.
116) B. Zareh-Desari, and B. Davoodi, "Assessing the lubrication performance of vegetable oil-based nano-lubricants for environmentally conscious metal forming processes,” J. Clean. Prod., 135 1198-1209 (2016). doi:10.1016/j.jclepro.2016.07.040.

117) M. Dienwiebel, and K. Pöhlmann, "Nanoscale evolution of sliding metal surfaces during running-in," Tribol. Lett., $27 \quad$ (3) 255-260 (2017). doi:10.1007/s11249-007-9216-y.

118) M.K.A. Ali, P. Fuming, H.A. Younus, M.A.A. Abdelkareem, F.A. Essa, A. Elagouz, and H. Xianjun, "Fuel economy in gasoline engines using al2o3/tio2 nanomaterials as nanolubricant additives," Appl. Energy, $211 \quad 461-478 \quad$ (2018). doi:10.1016/j.apenergy.2017.11.013.

119) O. V Makarova, T. Rajh, M.C. Thurnauer, A. Martin, and P.A. Kemme, "Surface modi cation of tio 2 nanoparticles for photochemical reduction of nitrobenzene,” Environ. Sci. Technol, 34 (22) 47974803 (2020). doi:10.1021/es001109.

120) M. Kumar, A. Afzal, and M.K. Ramis, "Investigation of physicochemical and tribological properties of tio2 nano-lubricant oil of different concentrations,” Tribol. - Finnish J. Tribol., 35 (3) 615 (2017).

121) M. Khadem, O. V Penkov, V.E. Pukha, M. V Maleyev, and D. Kim, "Ultra-thin carbon-based nanocomposite coatings for superior wear resistance under lubrication with nano-diamond additives," $R S C$ Adv., (62) 6-18 (2016).

122) L. Lüderitz, “An afm study of the interactions between colloidal particles,” 2011-2012 (2012). doi:10.14279/DEPOSITONCE-3373.

123) M. Miñana-Perez, A. Graciaa, J. Lachaise, and J.L. Salager, "Solubilization of polar oils with extended surfactants," Colloids Surfaces A Physicochem. Eng. Asp., 100 217-224 (1995). doi:10.1016/0927-7757(95)03186-H.

124) H.K. Ingvar Eide, Kolbjørn Zahlsen, "Identication and quanti cation of surfactants in oil using the novel method for chemical fingerprinting based on," Energy and Fuels, 20 (3) 1161-1164 (2019).

125) D.X. Peng, C.H. Chen, Y. Kang, Y.P. Chang, and S.Y. Chang, "Size effects of sio2 nanoparticles as oil additives on tribology of lubricant," Ind. Lubr. Tribol., $62 \quad$ (2) 111-120 (2010). doi:10.1108/00368791011025656.

126) W. Dai, B. Kheireddin, H. Gao, and H. Liang, "Roles of nanoparticles in oil lubrication," Tribol. Int., $102 \quad$ (05) 88-98 doi:10.1016/j.triboint.2016.05.020.

127) J. Zhang, and Y. Meng, "Boundary lubrication by adsorption film,” Friction, 3 (2) 115-147 (2015).

128) S.F. and G.F. Brown, "Lubricants , composition and additives,” Lubr. Technol., 1-8 (2016).

129) R. Rosentsveig, A. Gorodnev, N. Feuerstein, H. 
Friedman, A. Zak, N. Fleischer, J. Tannous, F. Dassenoy, and R. Tenne, "Fullerene-like mos 2 nanoparticles and their tribological behavior,” Tribol. Lett., 36 (2) 175-182 (2009). doi:10.1007/s11249009-9472-0.

130) R. Unnikrishnan, M.C. Jain, A.K. Harinarayan, and A.K. Mehta, "Additive-additive interaction: an xps study of the effect of zddp on the aw/ep characteristic of molybdenum based additives," Wear, 252 (3-4) 240-249 (2002). doi:10.1016/S00431648(01)00865-1.

131) L. Kolodziejczyk1, D. Martínez-Martínez1, "Surface-modified pd nanoparticles as a superior additive for lubrication,” J. Nanoparticle Res., 9 639645 (2015). https://www.secret.ly/privacy.

132) S.A.G. Watson, "Lubricant-Derived Ash - InEngine Sources and Opportunities for Reduction. Doctor of pilosophy in mechanical engineering at the massachusetts institute of technology,” 2010.

133) K. Lee, Y. Hwang, S. Cheong, L. Kwon, S. Kim, and J. Lee, "Performance evaluation of nanolubricants of fullerene nanoparticles in refrigeration mineral oil,” Curr. Appl. Phys., 9 (2 SUPPL.) 1-10 (2009). doi:10.1016/j.cap.2008.12.054.

134) Y. Xu, E. Hu, K. Hu, Y. Xu, and X. Hu, "Formation of an adsorption film of mos2 nanoparticles and dioctyl sebacate on a steel surface for alleviating friction and wear,” Tribol. Int., 92 (55) 172-183 (2015). doi:10.1016/j.triboint.2015.06.011.

135) X. Zheng, Y. Xu, J. Geng, Y. Peng, D. Olson, and $\mathrm{X}$. Hu, "Tribological behavior of fe3o4/mos2 nanocomposites additives in aqueous and oil phase media,” Tribol. Int., 102 79-87 (2016). doi:10.1016/j.triboint.2016.05.024.

136) L. Li, M. Kim, S. Lee, J. Kim, H. Kim, and D. Lee, "Study on surface modification of aluminum 6061 by multiple ultrasonic impact treatments," Int. J. Adv. Manuf. Technol., 96 (1-4) 1255-1264 (2018). doi:10.1007/s00170-018-1666-X.

137) E.O.L. Ettefaghi, H. Ahmadi, A. Rashidi, and S.S. Mohtasebi, "Investigation of the anti-wear properties of nano additives on sliding bearings of internal combustion engines,” Int. J. Precis. Eng. Manuf., 14 (5) 805-809 (2013). doi:10.1007/s12541013-0105-z.

138) C.P. Koshy, P.K. Rajendrakumar, and M.V. Thottackkad, "Evaluation of the tribological and thermo-physical properties of coconut oil added with mos2 nanoparticles at elevated temperatures," Wear, 330-331 288-308 doi:10.1016/j.wear.2014.12.044.

(2015).

139) N.G. Demas, E. V Timofeeva, J.L. Routbort, G.R. Fenske, and W.D. Downtown, "Tribological effects of bn and mos2 nanoparticls added to polyalphaolefin oil in piston skirt/cylinder liner test.," Int. Jt. Tribol. Conf., 47 (1) 10-21 (2012).

140) S. Asadauskas, J.M. Perez, and J.L. Duda, "Lubrication properties of castor oil - potential basestock for biodegradable lubricants,” Lubr. Eng., 53 (12) 35-40 (1997).

141) M.A. Kalam, H.H. Masjuki, M. Varman, and A.M. Liaquat, "Friction and wear characteristics of waste vegetable oil contaminated lubricants," Int. J. Mech. Mater. Eng., 6 (3) 431-436 (2011).

142) X. Zhou, X. Fu, H. Shi, and Z. Hu, "Lubricating properties of cyanex 302-modified mos2 microspheres in base oil 500 sn,” Lubr. Sci., 19 (1) 71-79 (2007). doi:10.1002/ls.32.

143) S.M. Alves, B.S. Barros, M.F. Trajano, K.S.B. Ribeiro, and E. Moura, "Tribological behavior of vegetable oil-based lubricants with nanoparticles of oxides in boundary lubrication conditions," Tribol. Int., $\quad 65 \quad 28-36 \quad$ (2013). doi:10.1016/j.triboint.2013.03.027.

144) A.K.G. A.K. Singh, N.K. Pandey, "Composition of insulating fluid and process for the preparation thereof, US Patents NO: 8,658,575.," 2014.

145) A.K.G. A.K. Singh, N.K. Pandey, "Composition of hydraulic fluid and process for the preparation thereof, U.S. Patent No. 8,034,751, 2011," 2011.

146) P.U. Aldana, B. Vacher, T. Le Mogne, M. Belin, B. Thiebaut, and F. Dassenoy, "Action mechanism of ws2 nanoparticles with zddp additive in boundary lubrication regime,” Tribol. Lett., 56 (2) 249-258 (2014). doi:10.1007/s11249-014-0405-1.

147) L. Gara, and Q. Zou, "Friction and wear characteristics of oil-based zno nanofluids," Tribol. Trans., $56 \quad$ (2) 236-244 (2013). doi:10.1080/10402004.2012.740148.

148) S. Bekal, and N.R. Bhat, "Bio-lubricant as an alternative to mineral oil for a ci engine-an experimental investigation with pongamia oil as a lubricant," Energy Sources, Part A Recover. Util. Environ. Eff., 34 (11) 1016-1026 (2012). doi:10.1080/15567031003735303.

149) A.K. Agarwal, "Biofuels (alcohols and biodiesel) applications as fuels for internal combustion engines,” Prog. Energy Combust. Sci., 33 (3) 233-271 (2007). doi:10.1016/j.pecs.2006.08.003.

150) N.F. Azman, S. Samion, M.A.A. Moen, M.K. Abdul Hamid, and M.N. Musa, "The anti-wear and extreme pressure performance of cuo and graphite nanoparticles as an additive in palm oil," Int. J. Struct. Integr., 10 (5) 714-725 (2019). doi:10.1108/IJSI-032019-0026.

151) A.K. Singh, "Castor oil-based lubricant reduces smoke emission in two-stroke engines," Ind. Crops Prod., $33 \quad$ (2) 287-295 (2011). doi:10.1016/j.indcrop.2010.12.014.

152) N.W.M. Zulkifli, M.A. Kalam, H.H. Masjuki, M. Shahabuddin, and R. Yunus, "Wear prevention characteristics of a palm oil-based tmp (trimethylolpropane) ester as an engine lubricant," Energy, $54 \quad 167-173 \quad$ (2013). 
doi:10.1016/j.energy.2013.01.038.

153) A. Adhvaryu, Z. Liu, and S.Z. Erhan, "Synthesis of novel alkoxylated triacylglycerols and their lubricant base oil properties," Ind. Crops Prod., 21 (1) 113-119 (2005). doi:10.1016/j.indcrop.2004.02.001.

154) K. Wagh, R. Halmare, and M. Suryawanshi, "Potential of non edible vegetable oils as an alternative lubricants in automotive applications," Int. J. Eng. Res. Appl., 2 (1) 1330-1345 (2012). doi:10.24001/ijcmes.icsesd2017.73.

155) S. Sriram, G and Arumugam, "Synthesis and characterization of rapeseed oil bio-lubricant dispersed with nano copper oxide," in: Proc. Inst. Mech. Eng. Part J J. Eng. Tribol., 2014: pp. 13081318. doi:10.1177/1350650114535384.

156) T. Luo, X. Wei, H. Zhao, G. Cai, and X. Zheng, "Tribology properties of al2o3/tio2 nanocomposites as lubricant additives," Ceram. Int., 40 (7 PART A) 10103-10109

(2014). doi:10.1016/j.ceramint.2014.03.181.

157) A.K. Jain, and A. Suhane, "Capability of biolubricants as alternative lubricant in industrial and maintenance applications," Int. J. Curr. Eng. Technol., 3 (1) 179-183 (2013).

158) A.C. Opia, M.K.B.A. Hamid, S. Syahrullail, A.B.A. Rahim, and C.A.N. Johnson, "Biomass as a potential source of sustainable fuel, chemical and tribological materials - overview," Mater. Today Proc., 1-18 (2021). doi:10.1016/j.matpr.2020.04.045.

159) A.C. Opia, A. Hamid, M. Kameil, Z. Hilmi, and C. Daud, "Tribological properties enhancement through organic carbon nanotubes as nanoparticle additives in boundary lubrication conditions," $J$. Teknol., 27 (December) 116-131 (2020).

160) M. Kalin, J. Kogovšek, and M. Remškar, "Nanoparticles as novel lubricating additives in a green, physically based lubrication technology for dlc coatings,” Wear, 303 (1-2) 480-485 (2013). doi:10.1016/j.wear.2013.03.009. 